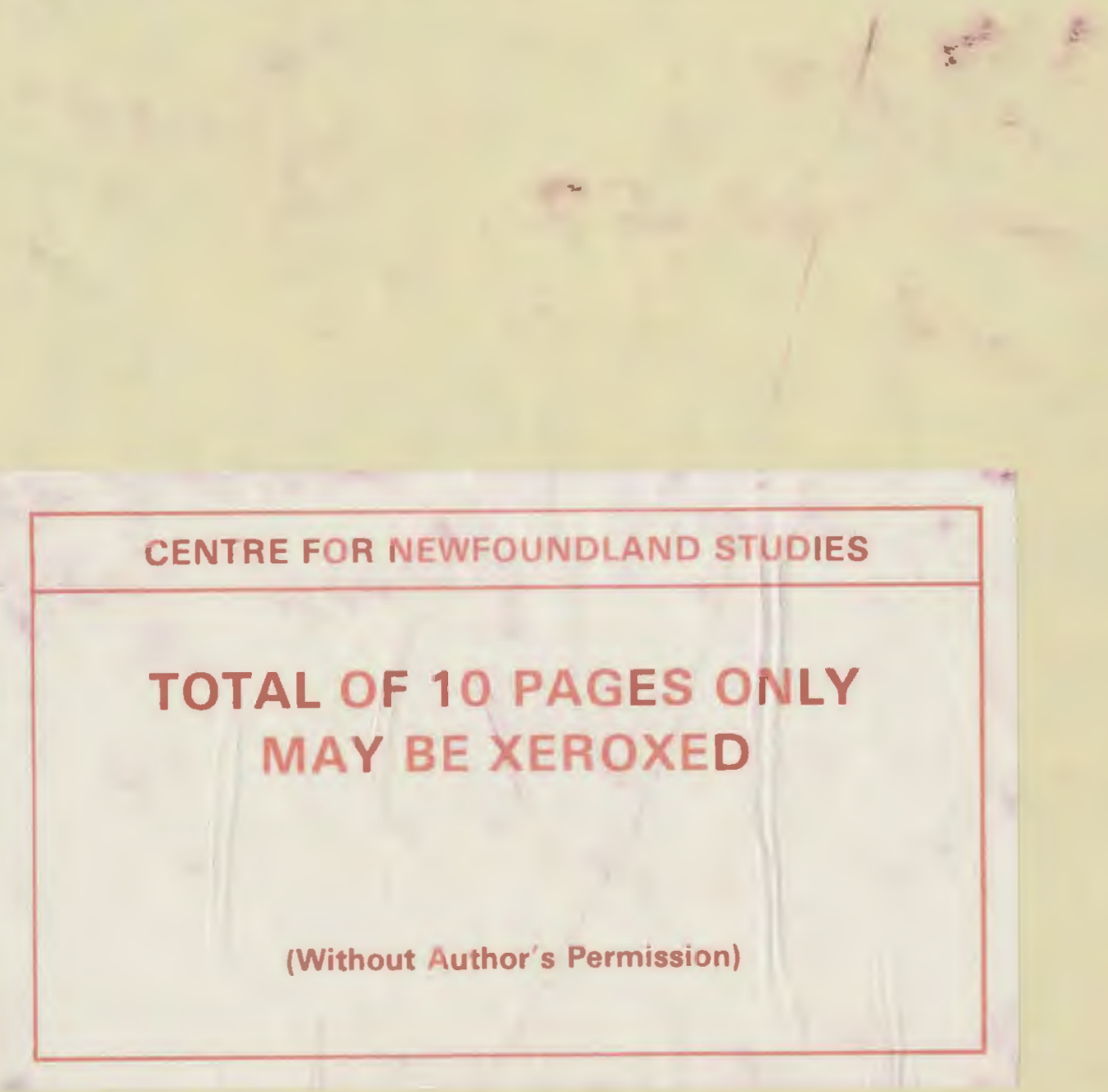

M. K. ALI, M.SC

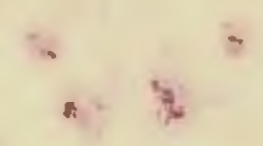




$$
\begin{gathered}
213576 \\
\text { C. } 1
\end{gathered}
$$

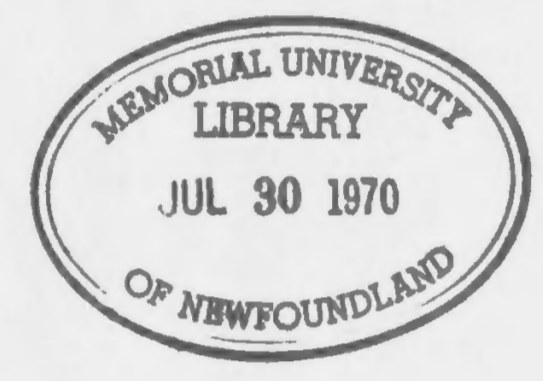




\section{THE EMISSION SPECTRUM OF DIATOMIC BISMUTH}

\section{by}

M. K. Ali, M.Sc.

Submitted in partial fulfilment of the requirements for the degree of Master of Science Memorial University of Newfoundland St. John's, Newfoundl and, Canada

October, 1969

(C) M.K. Ali 1973 
THIS THESIS HAS BEEN EXAMINED AND APPROVED BY:

\author{
Miss E. J. Altin, M.A., Ph.D. \\ Profess or of Physics \\ Universtty of Toronto
}

and

\author{
R. Tipping, M.S., Ph.D. \\ Assistant Professor of Physics \\ Memorial University of Newfoundland
}




\section{CONTENTS}

Page

List of Plates

v

Abs tract

vi

Chapter I. Introduction

1.1 Electronic Spectra of Homopolar Diatomic Molecules of Elements of the Fifth Group

1.2 Previous Work on the Electronic Band Spectrum of Diatomic Bismuth

1.3 The Present Investigation

Chapter II. Experimental Technique

2.1 Bausch and Lomb Dual Grating Spectrograph $\theta$

2.2 Raytheon Microwave Power Generator 10

$\begin{array}{lll}2.3 & \text { Discharge Tube } & 16\end{array}$

2.4 Experimental Procedure 16

2.5 Measurement of Spectra 19

Chapter III. Experimental Data and Analysis

3.1 Observed Emission Band Systems of $\mathrm{Bi}_{2}$

3.2 The $G+B$ System 22

3.3 The $H \rightarrow$ B System 27

3.4 The $I \rightarrow$ B System 30

3.5 The B $\rightarrow$ X System 33 
Chapter IV. Discussion on the Electronic States of $\mathrm{Bi}_{2}$

4.1 Summary of the Electronic States of $\mathrm{Bi}_{2}$

4.2 Electronic Configurations and Molecular Terms of $\mathrm{Bi}_{2}$

Appendi $x$

Acknowledgments :

66

References

67

General References

68 


\section{LIST OF PLATES}

Plate

I

II

III

IV

$V-V I I I$
Title

The $G \rightarrow B$ System of

Diatomic Bismuth

The $H \rightarrow B$ System of

Diatomic Bismuth

The I $\rightarrow$ B System of

Diatomic Bismuth

The $B \rightarrow X$ System of

Diatomic Bismuth

(Contact Spectrograms)

The $B \rightarrow X$ System of

Diatomic Bismuth

(Enlarged Spectrograms)
22

27

30

33

Page

34 


\section{ABSTRACT}

The emission spectrum of $\mathrm{Bi}_{2}$ was excited by irradiating bismuth vapor in a discharge tube by a high power microwave generator and photographed with a Bausch and Lomb dual grating spectrograph. Three new band systems have been observed and analyzed:

(i) The near infrared system $(G-B)$ in the region $\lambda 8820-8030 \AA$ consists of 15 bands whose frequencies are represented by the quantum expression

$$
\begin{aligned}
v= & 11869.5+107.0\left(v^{\prime}+\frac{1}{2}\right)-0.2\left(v^{\prime}+\frac{1}{2}\right)^{2} \\
& -\left[132.3\left(v^{\prime \prime}+\frac{1}{2}\right)-0.6\left(v^{\prime \prime}+\frac{1}{2}\right)^{2}\right] .
\end{aligned}
$$

(ii) The system $(H-B)$ in the region $\lambda 7050-6730 \AA$ consists of a single long $v "$ progression. The derived vibrational constants of this system are

$$
v_{00}=14851.6 \mathrm{~cm}^{-1} ; \omega_{e}^{\prime \prime}=134.0 \mathrm{~cm}^{-1} ; \omega_{e}^{\prime \prime} x_{e}^{\prime \prime}=0.34 \mathrm{~cm}^{-1} .
$$

(iii) The system $(I-B)$ in the region $\lambda 6570-6290 \AA$ consists of over 10 bands. The frequencies of the band heads are expressed as

$$
\begin{aligned}
v= & 15477.4+156.4\left(v^{\prime}+\frac{1}{2}\right)-6.1\left(v^{\prime}+\frac{1}{2}\right)^{2} \\
& -\left[132.4\left(v^{\prime \prime}+\frac{1}{2}\right)-0.3\left(v^{\prime \prime}+\frac{1}{2}\right)^{2}\right] .
\end{aligned}
$$

Since the lower state vibrational frequencies of these three systems agree closely with each other and also with the known upper 
state frequency of the $B$ - $X$ system, it is concluded that state $B$ is the common lower state of the new systems. The upper states of the new systems are designated as $G, H$, and I following the notation of Herzberg (1950) and Almy (1937) for the previously known electronic states of $\mathrm{Bi}_{2}$.

The known $B$ - $X$ system of $\mathrm{Bi}_{2}$ which was mainly studied in absorption (Almy and Sparks (1933); Nakamura and Shidei (1934)) has also been obtained in emission under the conditions mentioned above. Over 270 bands have been measured in the region $\lambda 7980-4830 \AA$. The new emission data of this system are in general agreement with the data obtained in absorption. The following expression is derived from the analysis of the emission data:

$$
\begin{aligned}
v= & 17739.5+132.571\left(v^{\prime}+\frac{3}{2}\right)-0.3271\left(v^{\prime}+\frac{3}{2}\right)^{2} \\
& +0.5240 \times 10^{-3}\left(v^{\prime}+\frac{3}{2}\right)^{3}-0.5324 \times 10^{-4}\left(v^{\prime}+\frac{3}{2}\right)^{4} \\
& +0.154 \times 10^{-5}\left(v^{\prime}+\frac{1}{2}\right)^{5} \\
& -\left[173.132\left(v^{\prime \prime}+\frac{1}{2}\right)-0.4156\left(v^{\prime \prime}+\frac{3}{2}\right)^{2}\right. \\
& +0.2437 \times 10^{-2}\left(v^{\prime \prime}+\frac{3}{2}\right)^{3}-0.8356 \times 10^{-4}\left(v^{\prime \prime}+\frac{1}{2}\right)^{4} \\
& \left.+0.72 \times 10^{-6}\left(v^{\prime \prime}+\frac{3}{2}\right)^{5}\right]
\end{aligned}
$$

In conclusion, a general summary of all the known electronic states of $\mathrm{Bi}_{2}$ is given. 


\section{CHAPTER I}

\section{INTRODUCTION}

1.1 Electronic Spectra of Homopolar Diatomic Molecules of Elements of the Fifth Group:

A great progress has been made in the last several decades in the experimental investigation and theoretical interpretation of the electronic band spectra of molecules. From a detailed investigation of the electronic spectrum of a molecule, one can derive, precisely, the electronic, vibrational and rotational levels of that molecule. From these again, one can obtain detailed information about the electronic structure (motion of electrons) and the vibration and rotation of the nuclei in the molecule. A knowledge of the electronic motions leads to the understanding of important properties such as chemical valence. From the vibrational frequencies and the corresponding anharmonicities, the forces between the atoms of the molecule and the heats of dissociation can be calculated. From a study of the rotational fine structure of the electronic bands of the molecule, the moments of inertia (hence the internuclear distances) and the nature of the coupling between the electronic and rotational motions of the molecule can be determined with great precision. The various properties of the individual molecules thus obtained by spectroscopic methods enable us to understand many of their physical and chemical properties. 
Molecules formed by the union of two atoms in the same group of the periodic table should, to a first approximation, exhibit similar spectra. In each atom of the group, the outermost shell of electrons is the same except for the principal quantum number, and the type of molecular binding and the kind of molecular states depend largely upon these electrons. But the relative positions of the energy levels and the type of electronic coupling in the molecular spectra depend also on the inner shells of electrons. For a correlation of the electronic states and the nature of the electronic coupling in the spectra of a series of homologous molecules, it is therefore necessary to discover as many electronic states as possible for each of the individual molecules and do the rotational analysis of bands of the various electronic transitions of the molecule.

Considering the electronic band spectra of homopolar diatomic molecules of the elements of the fifth group of the periodic table, a great deal of experimental work has been done, both in emission and absorption, on the molecules $\mathrm{N}_{2}, \mathrm{P}_{2}$ and $\mathrm{As}_{2}$. However, the work done on the heavier molecules $\mathrm{Sb}_{2}$ and $\mathrm{Bi}_{2}$ is not very extensive. Some work has been done mainly in absorption, but the work in emission is particularly very fragmentary. A knowledge of the electronic states so far identified for $\mathrm{N}_{2}, \mathrm{P}_{2}$ and $\mathrm{As}_{2}$ suggests that there is a considerable scope for further work on the electronic spectra of $\mathrm{Sb}_{2}$ and $\mathrm{Bi}_{2}$ in emission as well as in absorption. In view of this, a study of the emission spectrum of $\mathrm{Bi}_{2}$ was undertaken and the results of this study are presented in this thesis. 
1.2 Previous Work on the Electronic Band Spectrum of Diatomic Bismuth:

A1 though the characteristic absorption spectrum of molecular bismuth has been observed by a number of earlier researchers, no analysis of any of the band systems has been carried out prior to the work of Almy and Sparks (1933) (see also Almy and Sparks for earlier references). Almy and Sparks have photographed the absorption spectrum of diatomic bismuth in the spectral region $2110 \AA-7900 \AA$ by heating pure bismuth in an atmosphere of nitrogen in a carbon-tube furnace at temperatures from 850 to $1500^{\circ} \mathrm{C}$ and also by heating in an evacuated quartz tube up to $1200^{\circ} \mathrm{C}$. The spectrum has been analyzed into four discrete band systems. In addition, it consists of a continuum and a series of diffused bands. Following the notation used by Herzberg (1950) and Almy (1937), the details of the absorption spectrum of bismuth are briefly presented below. Table I-(a) summarizes mainly the results of the work of Almy and Sparks.

(1) The $B+X$ System: This system consists of over 300 bands in the region $4500 \AA-7900 \AA$. The bands in the region up to $7660 \AA$ have been assigned vibrational quantum numbers $v^{\prime}=59$ and $v^{\prime \prime}=55$. The wavenumbers $v$ of the band heads of the system are represented by the quantum expression,

$$
\begin{aligned}
v= & 17742.3+\left(132.205\left(v^{\prime}+\frac{1}{2}\right)-0.30090\left(v^{\prime}+\frac{1}{2}\right)^{2}-0.0004739\left(v^{\prime}+\frac{1}{2}\right)^{3}\right) \\
& -\left(172.708\left(v^{\prime \prime}+\frac{x_{2}}{2}\right)-0.3227\left(v^{\prime \prime}+\frac{1}{2}\right)^{2}-0.0023209\left(v^{\prime \prime}+\frac{1}{2}\right)^{3}-0.000013\left(v^{\prime \prime}+\frac{1}{2}\right)^{4}\right) .
\end{aligned}
$$


TABLE I-(a)

Known Electronic Band Systems of $\mathrm{Bi}_{2}$ Prior to the Present Work

\begin{tabular}{|c|c|c|c|c|c|c|}
\hline $\begin{array}{c}\text { Region } \\
(\AA)\end{array}$ & Transition* & $\mathrm{T}_{\mathrm{e}}^{\prime}$ & $\frac{\omega_{e}^{\prime}}{\left(\mathrm{cm}^{-1}\right)}$ & $\omega_{e}^{\prime \prime}$ & Remarks & References \\
\hline $4500-7900$ & $B+X$ & 17742.3 & 132.2 & 172.7 & $\begin{array}{l}\text { observed over } 300 \text { bands in the } \\
\text { temperature range } 850-1500^{\circ} \mathrm{C}\end{array}$ & 1,2 \\
\hline $2950-3400$ & $c+x$ & -32000 & & & $\begin{array}{l}C \text { is a reptisive state. } \\
\text { continuous absorption occurs at } \\
\text { temperatures above } 900^{\circ} \mathrm{C}\end{array}$ & 1 \\
\hline $2600-2900$ & $D \leftarrow x$ & 36457 & 157 & $\begin{array}{l}\left(\Delta G_{\frac{1}{2}}^{\prime \prime}=\right. \\
172.0)\end{array}$ & observed 40 bands at $-900^{\circ} \mathrm{C}$ & 1,2 \\
\hline $4000-4200$ & $E+B$ & 42252 & 129 & $\begin{array}{l}\left\langle\Delta G_{\frac{1}{2}}^{\prime \prime}=\right. \\
134.4\rangle\end{array}$ & $\begin{array}{l}\text { observed } 15 \text { bands at temperatures } \\
\text { above } 10000^{\circ} \text { only }\end{array}$ & 1 \\
\hline $4200-4500$ & & & & & $\begin{array}{l}\text { a series of diffused bands were } \\
\text { observed }\end{array}$ & 1 \\
\hline $2060-2270$ & $(F)+X$ & -46000 & & & only partially analyzed & 1,2 \\
\hline
\end{tabular}

*Designation of states is taken from Herziberg (1950) and Almy (1937).

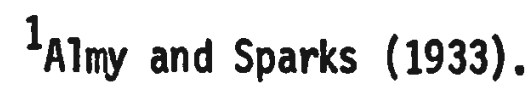

${ }^{2}$ Nakamura and Shidei (1934) 
The difference $v_{\text {observed }}{ }^{-v}$ calculated, the latter from the above formula, fluctuates from band to band. For some bands, this fluctuation is very small (less than $0.1 \mathrm{~cm}^{-1}$ ), whereas for others it is as large as $5 \mathrm{~cm}^{-1}$. At temperatures greater than $1000^{\circ} \mathrm{C}$, bismuth vapor becomes 1 uminous and a part of this system appears in thermal emission in the red region. (2) The $\mathrm{C}+X$ System: This consists of a region of continuous absorption which appears faint at about $900^{\circ} \mathrm{C}$ wi th a maximum of absorption at $3120 \AA$. At a temperature of $1050^{\circ} \mathrm{C}$, complete absorption occurs from $2600 \AA$ to $3400 \AA$. This continuous absorption is explained as arising from a transition from the initial ground state $X$ to a final repulsive state C.

(3) The $D+X$ System: This system extends from $2600 \AA$ to $2900 \AA$ and consists of 40 bands. It appears at about the same temperature as the $B+X$ system and the absorntion is much more intense and does not greatly extend with increasing temperature as is the $B+X$ system. The lower state vibrational constants of this system agree closely with those of the $B \leftarrow X$ system. The derived constants of the upper $D$ ciate are $\omega_{e}^{1}=157 \mathrm{~cm}^{-1}, \omega_{e}^{\prime} x_{e}^{\prime}=4.6 \mathrm{~cm}^{-1}$.

(4) The $E \leftarrow B$ System: This system which appears only at temperatures greater than $1000^{\circ} \mathrm{C}$ consists of 15 discrete bands in the region $4000 \AA$ $4200 \AA$. From the close agreement between the vibrational constants of the lower state of this system and those of the upper state of the $B+X$ system, it was concluded that the lower state is state $B$. Since the $B$ - $X$ system appears in thermal emission at temperatures above $1000^{\circ} \mathrm{C}$, 
it is certainly possible to have many bismuth molecules in state B by thermal excitation. The derived upper state vibrational constants of this system are $\omega_{e}^{\prime}=129 \mathrm{~cm}^{-1}, \omega_{e}^{\prime} x_{e}^{\prime}=9.7 \mathrm{~cm}^{-1}$. (5) Diffuse Band in the Region $4200 \AA-4500 \AA$ : These bands are probably due to a transition from a repulsive state, which is presumably crossed by state $E$, to the lower state $B$.

(6) The $(F)+X$ System: This system occurs at temperatures of about $825^{\circ} \mathrm{C}$ in the region $2060 \AA-2270 \AA$. The bands are diffuse in appearance and a partial analysis suggests that a presumably $v$ " progression has the same vibrational intervals as state $X$. The data are insufficient to make any definite conclusion about the upper vibrational level.

Nakamura and Shidei (1934) also observed the band systems $B$ - $X$, $D-X$ and $(F)$ - X of diatomic bismuth in absorption (Table I-(a)). Their independent analyses of systems $B \leftarrow X$ and $D \leftarrow X$ are in agreement in general with those of Almy and Sparks.

\subsection{The Present Investigation:}

In the present investigation, the emission spectrum of diatomic bismuth was excited by irradiating bismuth vapor by a high power microwave generator. The spectrum revealed the existence of three new band systems of $\mathrm{Bi}_{2}$ which occur in the following regions: (i) $\lambda 8820-8030 \AA$ $($ system $G+B),($ ii) $\lambda 7050-6730 \AA$ (system $H \leftarrow B$ ) and, (iii) $\lambda 6570-$ $6290 \AA$ (system $I+B)$. Vibrational analyses of all the three systems have been carried out and the vibrational constants derived. In addition, the $\mathrm{B}-\mathrm{X}$ system of $\mathrm{Bi}_{2}$ which was studied previously in absorption 
(Section 1.2) was also obtained in emission in the region $\lambda 7980-4830 \AA$. Using the new emission data of this system which are in general agreement with the absorption data, accurate vibrational constants are derived. Finally, all the known electronic states of $\mathrm{Bi}_{2}$ are summarized. 


\section{CHAPTER II}

\section{EXPERIMENTAL TECHNIQUE}

The emission spectrum of diatomic bismuth was excited with the use of microwave radiation on a heated quartz discharge tube containing molten bismuth. A brief description of the apparatus used and of the experimental procedure adopted is given in the present chapter.

\subsection{Bäusch and Lomb Dual Grating Spectrograph:}

A11 the spectra were photographed on a modified Bausch and Lomb Dual Grating Spectrograph. The schematic diagram of the spectrograph is shown in Fig. I. This instrument is of the littrow type with a large spherical mirror as collimator which has a radius of curvature of $200 \mathrm{~cm}$. Two echelle-type plane gratings, having a ruled area of $102 \mathrm{~mm} \times 128 \mathrm{~mm}$ each, one with 1200 and the other with 600 grooves per $\mathrm{mm}$, are provided for the spectrograph. These gratings are mounted back to back in a rotatable turret. Light from a source (not shown in the Fig.) after passing through the adjustable slit $S$ and getting reflected at the plane mirror $M$ is incident on the collimator SM. It is then dispersed by the grating $G$ and later focussed by the collimator onto the photographic plate $P$. Against a vertical scale fitted with the spectrograph, the plate holder can be raised or lowered either manually or by an automatic device co-ordinated with the opening and closing operations of the slit. The spectra were photographed with a slit width of $0.1 \mathrm{~mm}$ 

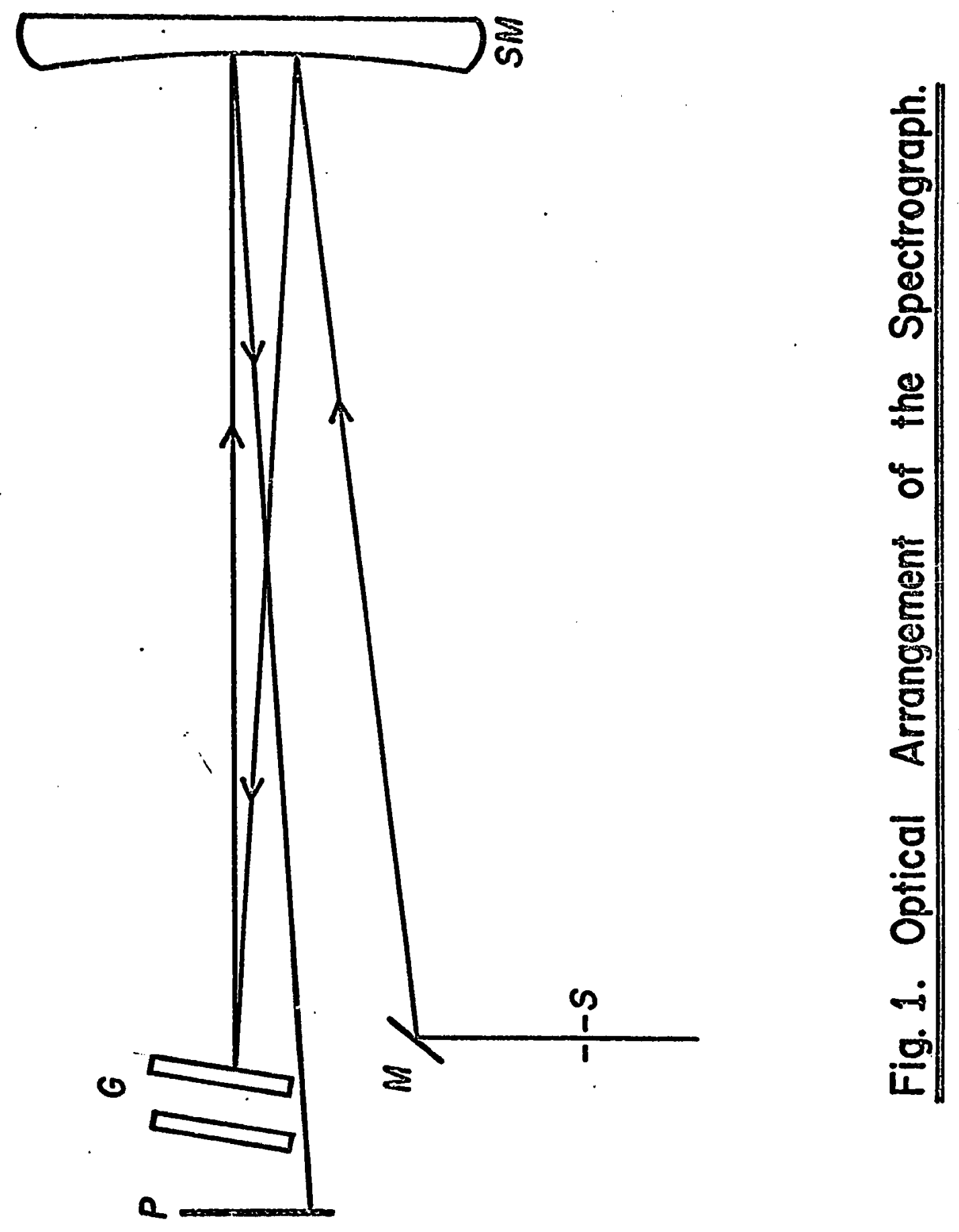
(which corresponds to 10 divisions on the drum). Out of the two gratings, the one with 1200 grooves per $\mathrm{mm}$ and having the following specifications was used in the present investigation:

$\begin{array}{ll}\text { Blazed wave length } & 1.0 \text { micron (first order) } \\ \text { Blaze angle } & 36^{\circ} 52^{\prime} \\ \text { Resolving Power } & 70 \% \text { of the theoretical value } \\ & (153600 \text { in the first order) } \\ & 62 \% \text { at } 9000 \AA \\ \text { Efficiency } & 66 \% \text { at } 1.0 \text { micron } \\ & 70 \% \text { at } 1.1 \text { microns } \\ \text { Ghost intensity } & 1.0 \% \text { of parent line in the } \\ & 2 n d \text { order at } 5461 \AA .\end{array}$

The numerical aperture of the spectrograph is $f / 15.5$ and the measured wavelength dispersions are as follows: $3.7 \AA / m m$ at $7530 \AA$ in the first order; $1.8 \AA / \mathrm{mm}$ at $4740 \AA$ in the second order; and $1.3 \AA / \mathrm{mm}$ at $6420 \AA$ in the second order.

\subsection{Raytheon Microwave Power Generator:}

Microwave radiation used in the present work for the excitation of the emission spectrum of bismuth was obtained from a microwave power generator model PGM-100 supplied by Raytheon Company, Waltham, Massachusetts, U. S. A. In Fig. 2 is represented a schematic diagram of the experimental setup which consists essentially of the microwave power generator $P G$, its accessories (filter unit $F$, waveguide $G$, and horn $H$ ), 

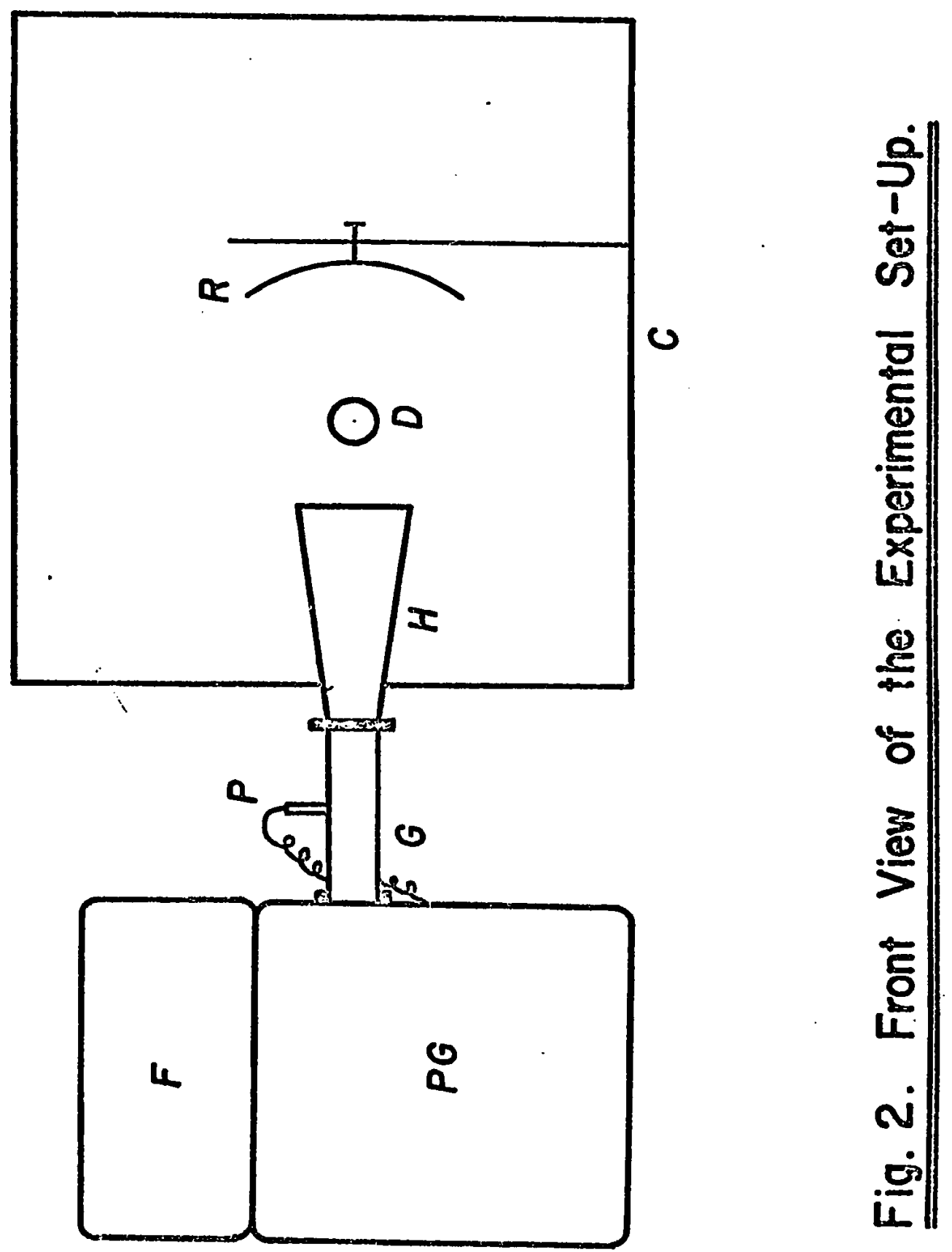


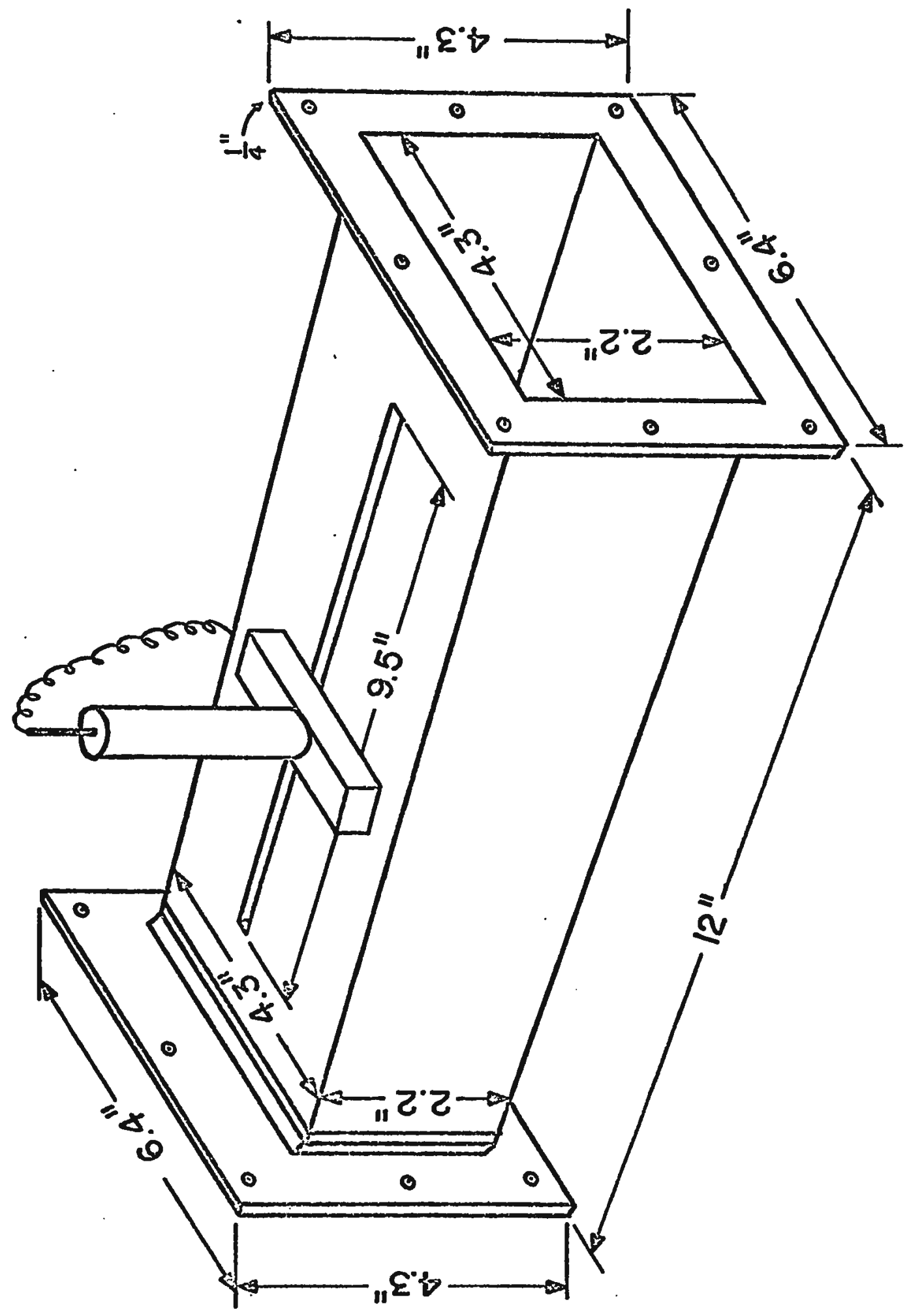

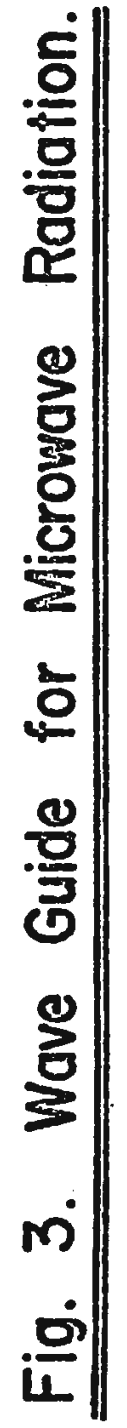




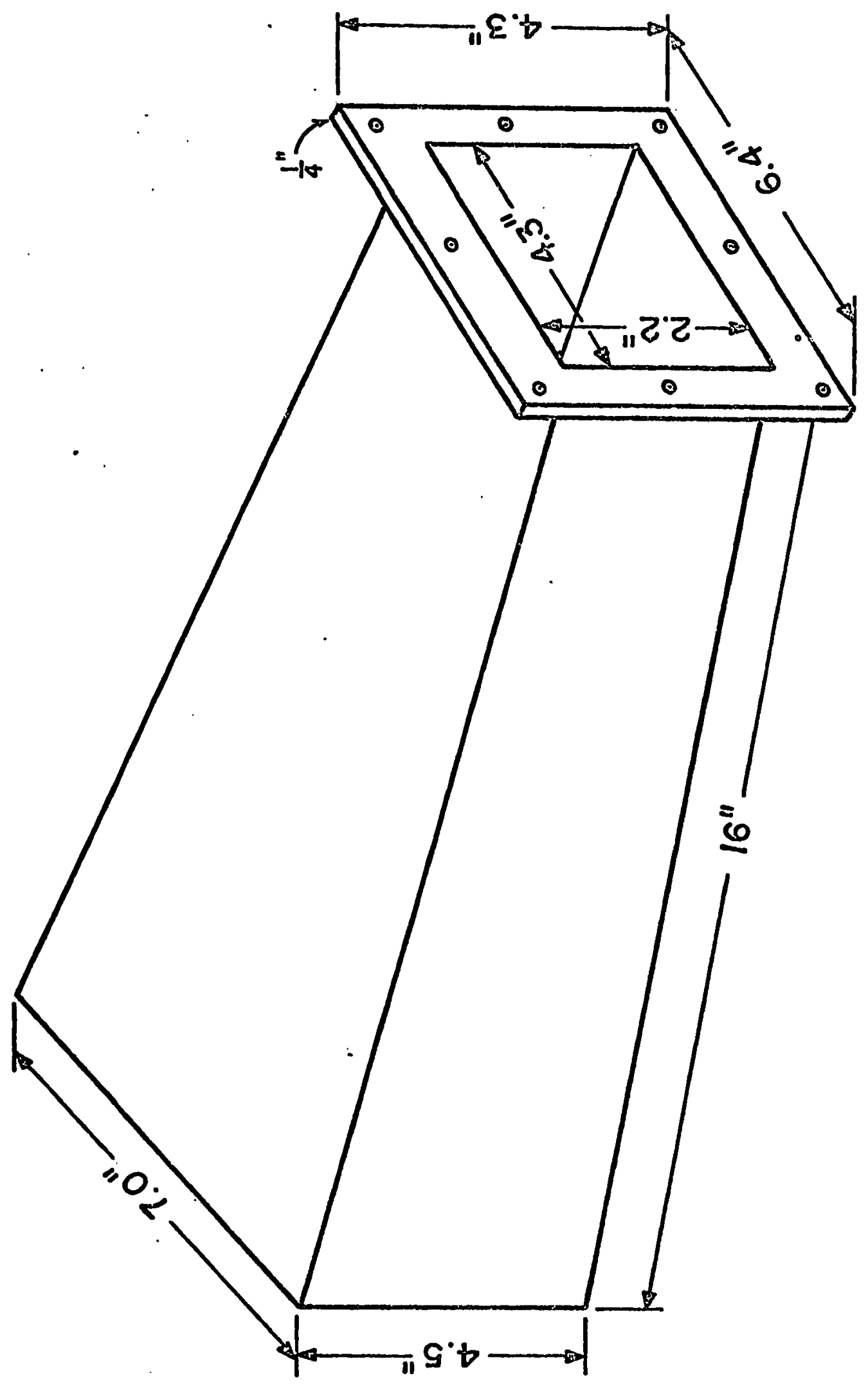

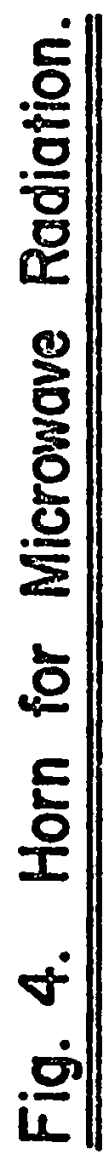




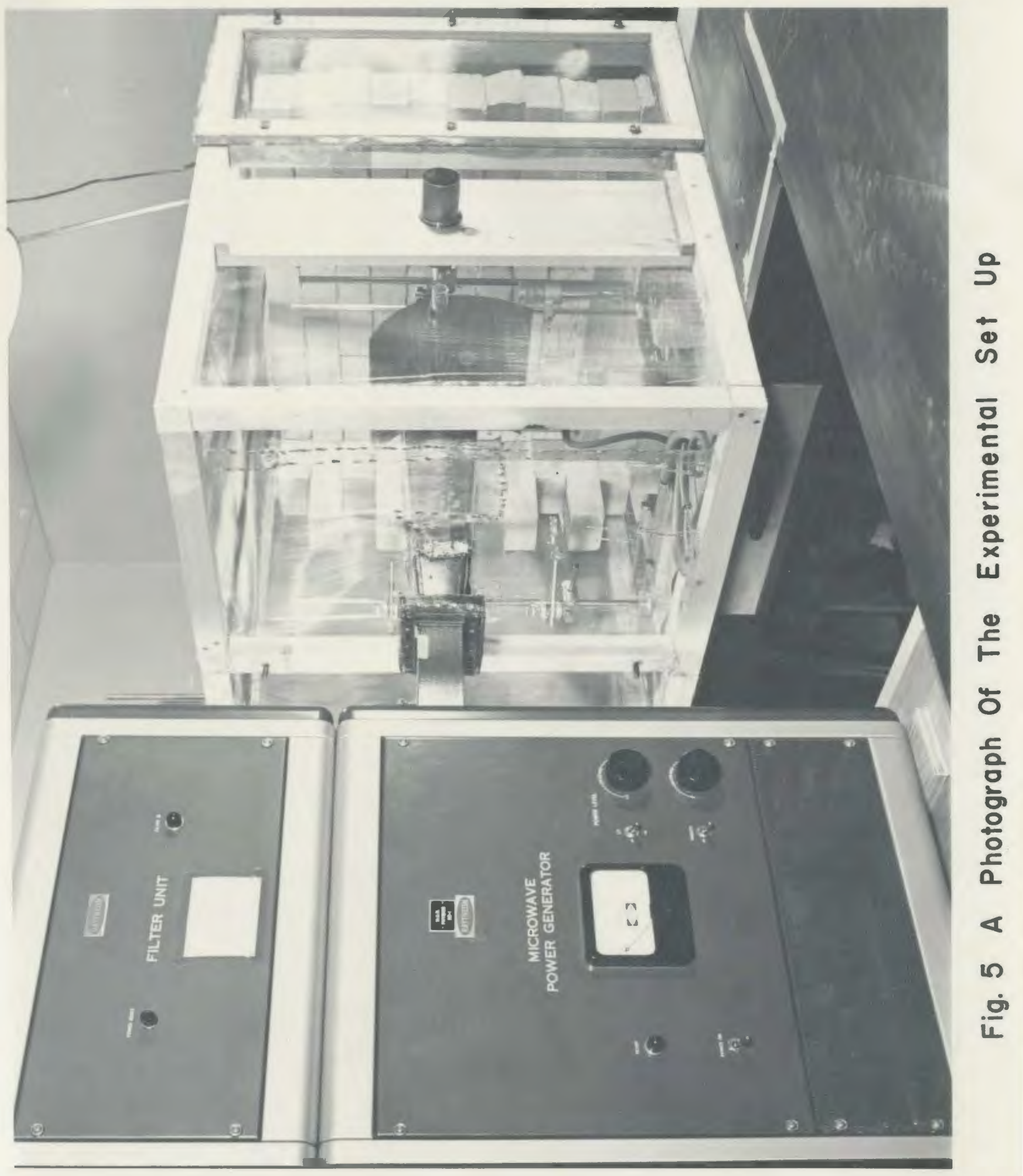


the discharge tube $D$, the metallic reflector $R$ and the microwave radiation cage $C$. The microwave power generator is essentially comprised of a fixed frequency, air-cooled, $\mathrm{CW}$-type magnetron oscillator. The magnetron is provided with a full wave rectified (120 cycles) power supply unit which employs a magnetic regulator to hold the average anode current. Consequently, the power output is virtually constant through normal line fluctuations and variations of magnetron impedence with load and life. The filter network $F$ of the generator can be switched into the magnetron plate supply to provide a microwave power output with a modulation of about $10 \%$ in the detected R.F. envelope. The microwave power generator, with its filter in, has an output power supply in the range 250 to 800 watts at a frequency of $2450 \pm 25 \mathrm{MHz}$. The generator $P G$ is fitted with the waveguide $G$ which in turn is connected with the horn $H$. The waveguide and the horn are constructed of brass plates of thickness 0.125 " and $0.03^{\prime \prime}$, respectively. The details of construction of these are diagrammatically represented in Figs. 3 and 4 , respectively. The wavelength of the radiation in the guide is $14.8 \mathrm{~cm}$. A photograph of the experimental setup excluding the spectrograph is shown in Fig. 5.

To avoid the hazards of microwave radiation, the horn, the discharge tube and the reflector were shielded in a rectangular radiation cage C (Figs. 2 and 5) of size $40^{\prime \prime} \times 40^{\prime \prime} \times 29^{\prime \prime}$ made of copper screen of mesh size $0.1 \mathrm{~cm} \times 0.15 \mathrm{~cm}$. To absorb scattered radiation inside the cage, a rubber pad was spread on the bottom surface of the cage and bricks made of clay were placed inside the cage along the wall behind the reflector $R$. 


\subsection{Discharge Tube:}

The electrodeless quartz discharge tube $D$ used in the present investigation is diagrammatically represented in Fig. 6. It is 18" long and $25 \mathrm{~mm}$ in inner diameter. One end of the discharge tube was joined with pyrex tubing through a graded seal. A circular quartz window $W$ of thickness $2 \mathrm{~mm}$ was sealed to the other end. The pyrex tubing was connected to a high vacuum pumping system through a liquid nitrogen trap T. Before the pyrex tubing was sealed to the liquid nitrogen trap, a sufficient quantity of pure bismuth in the form of shots, supplied by American Smelting and Refining Company, New Jersey, was placed in the discharge tube.

\subsection{Experimental Procedure:}

The quartz discharge tube containing bismuth was optically aligned with respect to the slit of the spectrograph so that the radiation from the discharge tube filled the collimator uniformly. The pyrex tubing connected to the liquid nitrogen trap (Fig. 6) was ultimately joined to the pumping system with a small rubber pressure tubing. The discharge tube was continuously evacuated during the experiment. When the vacuum reached approximately $5 \times 10^{-7}$ torr, the discharge tube was heated in the central portion over a length of $10 "$ with a special bunsen burner to produce the requisite amount of bismuth vapor. It was then irradiated with microwave radiation from the generator. The position of the reflector was adjusted as described below to obtain maximum intensity of the discharge. The characteristic color of the discharge was bluish 
$-17$.
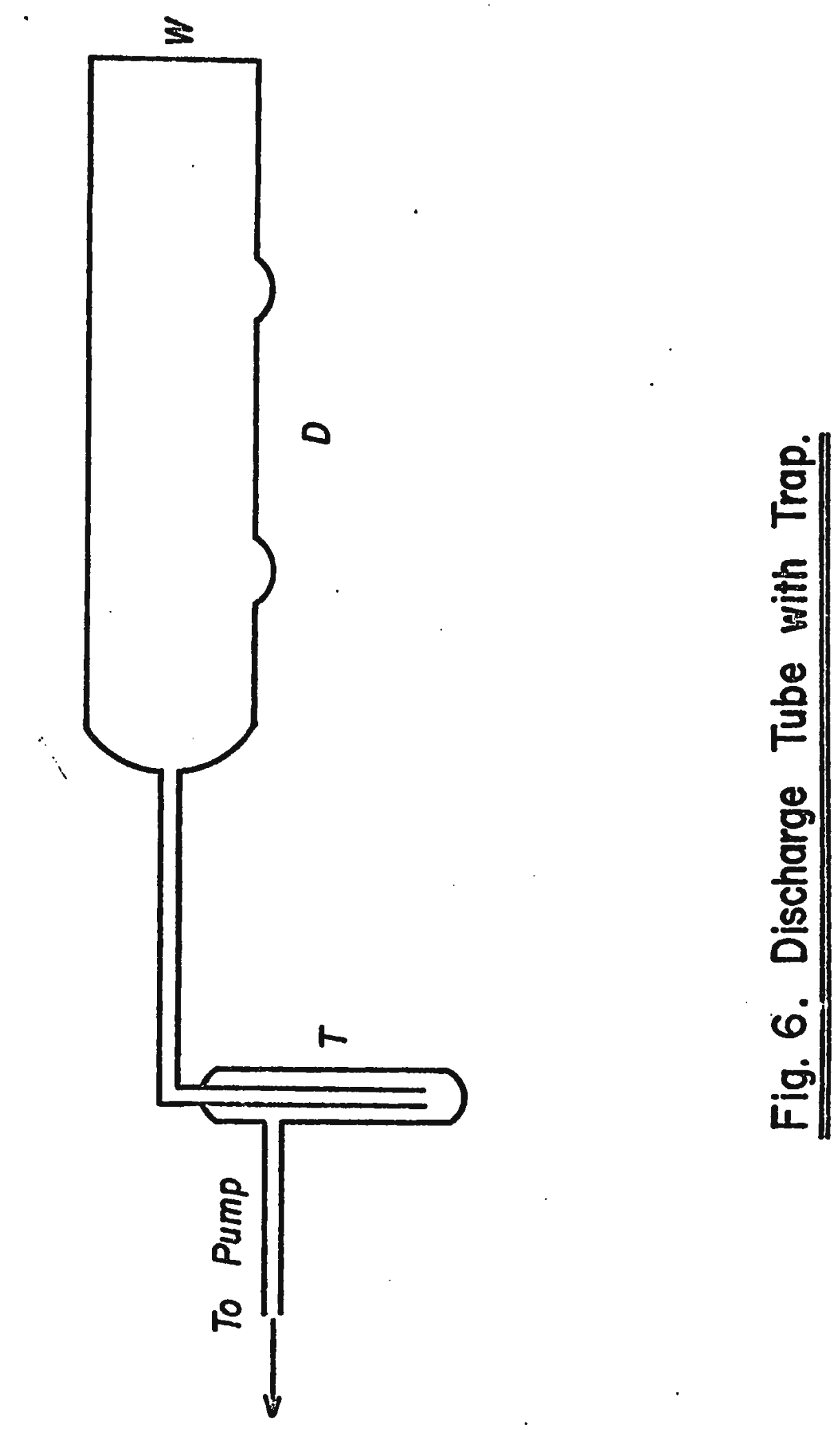
white. At times it was necessary to start the discharge with the help of a tesla coil. Condensation of bismuth on the window of the discharge tube was prevented by heating the window.

The details of finding a suitable position for the reflector which concentrates the microwave radiation on the discharge tube are as follows: A suitable position of the reflector with respect to the discharge tube and the horn was found so that the standing wave ratio VSWR (hereafter called $\rho$ ) in the wave guide was minimum when the discharge was on. To check $p$, a probe P (Figs. 2 and 3 ) which could be moved in the slot $S$ of the wave guide was read on a Wheatstone bridge circuit. According to the manufacturer's instructions, $p$ should not exceed 2 for the operation in the phase for the maximum power output. To find $p$ in the wave guide, a graph was plotted between probe distances along the wave guide and the corresponding resistances required to balance the Wheatstone bridge. This graph had several maxima and minima positions. Since the probe was not calibrated, square roots of the ratios between the resistances corresponding to maxima and minima of the graph were used for $p$ 's. However, it must be mentioned here that this simplification is not entirely justified. The values of $p ! s$ were found to lie between 1.26 and 1.31. Using a value of 1.31 for $\rho_{,} P_{r}$ the power received was calculated using the formula $P_{r}=P_{a}\left(4 p /(1+p)^{2}\right)$ where $P_{a}$ is the power available. The microwave power generator was used at an anode current of 260 ma which corresponded to $P_{a}$ equal to 755 watts. This value of $\mathrm{P}_{\mathrm{a}}$ was taken from a calibration curve obtained previously in our laboratories using a water load in conjunction with the microwave 
power generator. The corresponding value of $P_{r}$ was of the order of 740 watts.

The spectra were photographed with the Bausch and Lomb Grating Spectrograph (described in section 2.1) in the first and second orders of the grating $(12001 i n e s / \mathrm{mm})$. Kodak photographic plates of types 103a-0, panchromatic $B$ and $1-N$ were used to record the spectra. The exposure times ranged from $\frac{1}{2}$ hour to $2 \frac{1}{2}$ hours. A d.c. iron arc was used as a reference source and the iron lines were photographed in juxtaposition of the spectrum under investigation using a Hartmann diaphragm in front of the slit of the spectrograph.

\subsection{Measurement of Spectra:}

The spectra were measured using a linear comparator, Model 1205C, supplied by Gaertner Optical Instrumentation Company. Using iron arc lines as wavelength standards and the second order equation $\lambda=\lambda_{0}+a\left(d_{0}-d\right)+b\left(d_{0}-d\right)^{2}$, the wavelengths of the band heads $\left(\lambda_{a i r}\right)$ were calculated. In the above formula, d's stand for comparator scale readings and $\lambda$ 's for the corresponding wavelengths. Constants $\lambda_{0}$, a and b were determined by substituting in the above formula the $\lambda$ 's and d's of three known sharp reference lines. In a particular spectral region, the positions of band heads and a number of iron arc lines were measured. In a certain wavelength range, three sharp standard iron arc lines were used to calculate the constants $\lambda_{0}$, $a$ and $b$. The accuracy of the constants was tested by calculating back the $\lambda^{\prime} s$ of the other reference lines whose d's were measured in that range. When the calculated 
$\lambda$ 's started differing from the corresponding standard values by a factor more than $0.02 \AA$, another suitable set of three iron arc lines were used for calculating $\lambda$ 's of next band heads. The $\lambda_{\text {air }}$ thus obtained was then converted to $\lambda_{\text {vac }}$ by using the formula

$$
\lambda_{\text {vac }}=\lambda_{\text {air }}+\lambda_{\text {air }}\left(2726.43+\frac{12.288}{\lambda_{\text {air }}^{2} \times 10^{-8}}+\frac{0.3555}{\lambda_{\text {air }}^{4} \times 10^{-16}}\right) \times 10^{-7} .
$$

This formula was used by Kayser (1944) to prepare the tables for $\lambda_{\text {air }}$ and $\nu_{\text {vac }} \mathrm{cm}^{-1}$. The reciprocal of $\lambda_{\text {vac }}$ gave $\nu_{\text {vac }}\left(\mathrm{cm}^{-1}\right)$ for the band heads. These calculations were done using a Hewlett-Packard Calculator, Model 9100A. This procedure was found to be faster than obtaining the vacuum wave numbers from Kayser's tables when a large number of conversions is involved. 


\section{CHAPTER III}

\section{EXPERIMENTAL DATA AND ANALYSIS}

\subsection{Observed Emission Band Systems of $\mathrm{Bi}_{2}$ :}

In this chapter, the new experimental data on the emission spectrum of $\mathrm{Bi}_{2}$ and details of the vibrational analyses of three new band systems as well as those of system B - X will be presented. As mentioned in Chapter $I$, the new band systems are designated as $G \rightarrow B$, $H \rightarrow B$, and $I \rightarrow B$. Equations which are applicable to the analys is of the vibrational structure of electronic band systems are summarized in the Appendix. The vibrational analyses of all band sys tems mentioned here were carried out by standard procedures described by Herzberg (1950) and Jevons (1932).

Most of the details of the experimental technique used in obtaining the band systems mentioned above are described in Chapter II. Details of recording the spectra are briefly summarized below. The $G-B, H-B$, and I - B systems which occur in the spectral regions $\lambda 8820-8030 \AA, \lambda 7050-6730 \AA$, and $\lambda 6570$ - $6290 \AA$, respectively, were photographed in the first order of the grating spectrograph using Kodak 1-N plates. Second order iron arc lines were used as standards for the G - B system and first order iron arc lines were used for the other two systems. Different parts of the $B-X$ system which occur in the region $\lambda 7980-4830 \AA$ were photographed on Kodak 1-N, Panchromatic B, and 103 a-0 plates; and both first order and second 
( $a$ and $b$ : contact spectrograms; $C, d$ and $e$ : enlarged spectrograms;

$\mathrm{Bi}_{2}$ spectrum: first order; $\mathrm{Fe}$ arc spectrum: second order.)

Fe arc 4408.4

4267.0

4107.5

a

प1

1

Fe arc $4078 \quad 4024$

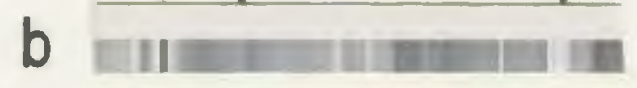

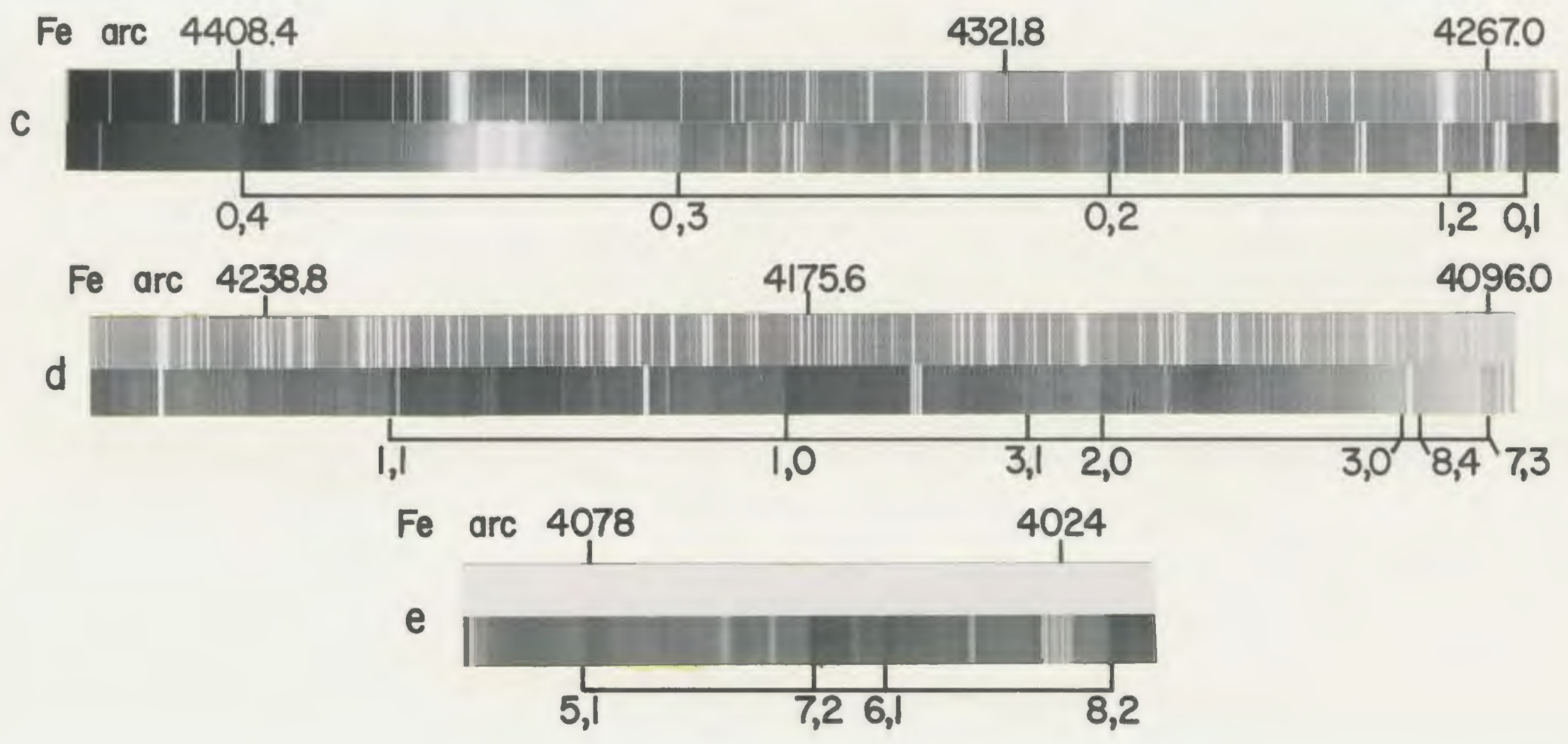


order iron arc lines were used as standards. To avoid overlapping of different orders of the grating, Corning filters CS-3-66 and CS-0-54 and Kodak filters $2 A$ and 26 were used. The exposure time was approximately $2 \frac{1}{2}$ hours for system $G$ - B and was $3 / 4$ hour for systems $H-B$ and $I$ - B. For system B - $X$, the exposure time varied from $\frac{1}{2}$ to 1 hour. The intensities of the bands of the four systems reported in this chapter are only visual estimates. These should not be considered very accurate since the sensitivities of different photographic plates in different wave length regions vary considerably from each other. For numerical calculations, an IBM 360 computer was used in addition to the Hewlett-Packard Calculator Model 9100.

\subsection{The $G \rightarrow B$ System:}

The near infrared G - B system which consists of about 15 bands degraded toward larger wavelengths is reproduced in plate I where strips $a$ and $b$ are contact spectrograms, and strips $c, d$, and $e$ are enlarged spectrograms. A few second order wavelengths of iron arc lines are marked in the spectrum to indicate the spectral region. The wavelengths and the vacuum wave numbers of all band heads are listed in Table 1. Vibrational quantum numbers assigned in this Table were obtained by fitting the wave numbers of band heads into a vibrational scheme. The vibrational scheme, extending to $v^{\prime}=8$ and $v^{\prime \prime}=4$, is shown in Table II. The bands fall into the usual Franck-Condon parabola. The vibrational quantum numbers of band heads are also marked for the enlarged spectrograms of plate I. 
TABLE I

Band Heads of the G - B System in the Region $\lambda 8820-8030 \AA$

\begin{tabular}{|c|c|c|c|c|c|}
\hline$\lambda_{\operatorname{air}}(A)$ & $v_{v a c}\left(\mathrm{~cm}^{-1}\right)$ & Intensity* & $v !$ & $v^{\prime \prime}$ & $\nu_{\text {obs }}{ }^{-\nu_{c a l c}}$ \\
\hline 8815.44 & 11340.6 & $w$ & 0 & 4 & 0.8 \\
\hline 8717.75 & 11467.7 & s & 0 & 3 & 0.4 \\
\hline 8620.93 & 11596.5 & m & 0 & 2 & 0.5 \\
\hline 8542.49 & 11703.0 & w & 1 & 2 & 0.4 \\
\hline 8525.68 & 11726.1 & w & 0 & 1 & 0.2 \\
\hline 8448.77 & 11832.8 & w & $1 ;$ & 1 & 0.3 \\
\hline 8356.87 & 11962.9 & $m$ & 1 & 0 & -0.7 \\
\hline 8301.16 & 12043.2 & $m$ & 3 & 1 & -0.6 \\
\hline 8283.30 & 12069.2 & m & 2 & 0 & -0.6 \\
\hline 8211.30 & 12175.0 & $w w^{* *}$ & 3 & 0 & -0.6 \\
\hline 8207.10 & 12181.2 & w & 8 & 4 & -0.2 \\
\hline 8192.08 & 12203.6 & $w$ & 7. & 3 & -1.5 \\
\hline 8158.70 & 12253.5 & ww & 5 , & 1 & -1.4 \\
\hline 8107.38 & 12331.1 & m & 7 & 2 & -2.7 \\
\hline 8088.55 & 12359.8 & ww & 6 & $\overline{1}$ & 0.3 \\
\hline 8039.19 & 12435.7 & m & 8 & 2 & -1.9 \\
\hline
\end{tabular}

* vs: very strong

s: strong

$\mathrm{m}:$ medium w: weak

w: very weak

** : superposed by an atomic line 


\section{TABLE II}

Vibrational Scheme of the G-B System

\begin{tabular}{|c|c|c|c|c|c|c|c|c|c|c|}
\hline $\begin{array}{l}v^{\prime \prime} \\
v^{\prime}\end{array}$ & 0 & & 1 & & 2 & & 3 & & 4 & Mean $\Delta G_{v+\frac{1}{2}}^{\prime}$ \\
\hline 0 & & & $\begin{array}{c}11726.1 \\
106.7\end{array}$ & 129.6 & $\begin{array}{c}11596.5 \\
106.5\end{array}$ & 128.8 & 11467.7 & 127.1 & 11340.6 & 106.6 \\
\hline 1 & $\begin{array}{c}11962.9 \\
106.3\end{array}$ & 130.1 & 11832.8 & 129.8 & 11703.0 & & & & & 106.3 \\
\hline 2 & $\begin{array}{c}12069.2 \\
105.8\end{array}$ & & & & & & & & & 105.8 \\
\hline $\begin{array}{l}3 \\
4\end{array}$ & 12175.0 & 131.8 & 12043.2 & & & & & & & \\
\hline $\begin{array}{l}5 \\
6\end{array}$ & & & $\begin{array}{c}12253.5 \\
106.3 \\
12359.8\end{array}$ & & & & & & & 106.3 \\
\hline $\begin{array}{l}7 \\
8\end{array}$ & & & & & $\begin{array}{c}12331.1 \\
104.6 \\
12435.7\end{array}$ & 127.5 & 12203.6 & & 12181.2 & 104.6 \\
\hline $\begin{array}{c}\text { Mean } \\
\Delta G_{v+1 / 2}^{\prime \prime}\end{array}$ & & 131.0 & & 129.7 & & 128.2 & & 127.1 & & \\
\hline
\end{tabular}


Plots of the mean values of vibrational intervals $\Delta G_{v}+\frac{z_{2}}{2}$ against the corresponding $v+\frac{1}{2}$ values for various states of $\mathrm{Bi}_{2}$ are shown in Fig. 7. The vibrational intervals of the lower and upper states of this system were obtained using only the frequencies of the bands $(0,4),(0,3),(0,2),(1,2),(0,1),(1,1),(1,0),(3,1),(2,0)$, and $(3,0)$ because the frequencies of the other bands are considered to be less accurate. The plots for the lower and upper states of this system indicate that the vibrational terms $G(v)$ can be expressed as

$$
G(v)=\omega_{e}\left(v+\frac{3}{2}\right)-\omega_{e} x_{e}\left(v+\frac{3}{2}\right)^{2} \text {. }
$$

The slopes and intercepts of the straight lines obtained by a least square fit for this system (Fig. 7) give the values of $-2 \omega_{e} x_{e}$ and $\omega_{e}-\omega_{e} x_{e}$, respectively (eq. 9, Appendix). The values of the vibrational constants thus obtained for the $G$ - B system are

$$
\begin{array}{ll}
\omega_{e}^{\prime}=107.0 \mathrm{~cm}^{-1} & \omega_{e}^{\prime \prime}=132.3 \mathrm{~cm}^{-1} \\
\omega_{e}^{\prime} x_{e}^{\prime}=0.2 \mathrm{~cm}^{-1} & \omega_{e}^{\prime \prime} x_{e}^{\prime \prime}=0.6 \mathrm{~cm}^{-1} .
\end{array}
$$

The system origin $v_{e}$ (eq. 2, Appendix) was determined individually by using the calculated values of $G^{\prime}(v)$ and $G^{\prime \prime}(v)$ in conjunction with the frequencies $v$ of the 10 band heads mentioned above. The mean value of $v_{e}$ thus obtained was found to be $11869.5 \mathrm{~cm}^{-1}$. Finally, the wave numbers of the band heads of the $G-B$ system are represented by the formula 


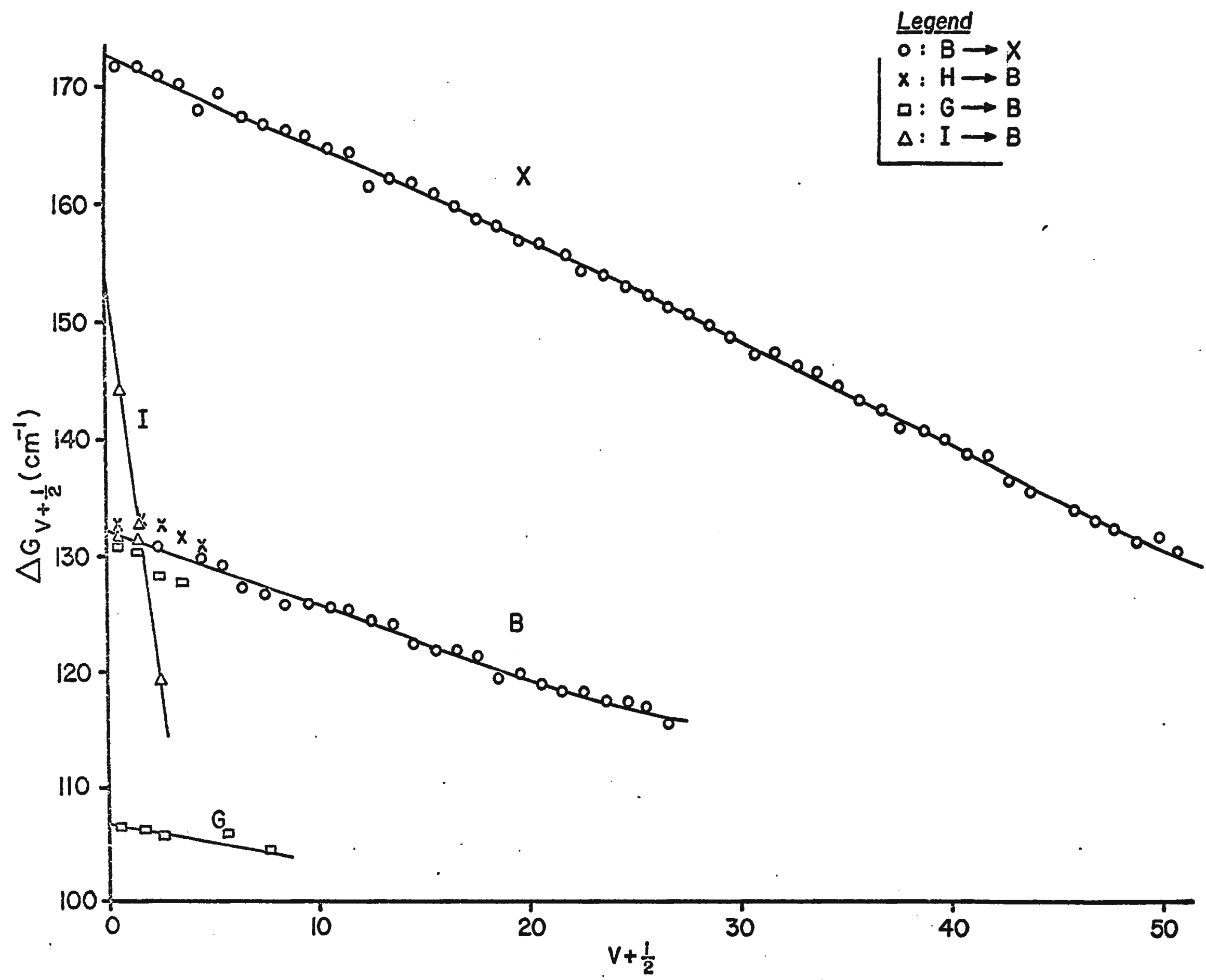

Fig.7. Mean $\triangle G$ curves of observed staies of diatomic bismuth ( plotted against $V+\frac{1}{2}$ ) 
(a: contact spectrogram; $b$ : enlarged spectrogram. Both Fe arc and $\mathrm{Bi}_{2}$ spectra are photographed in the first order of the grating. Bands degraded to longer wavelengths belong to the $\mathrm{B} \rightarrow \mathrm{X}$ system. )
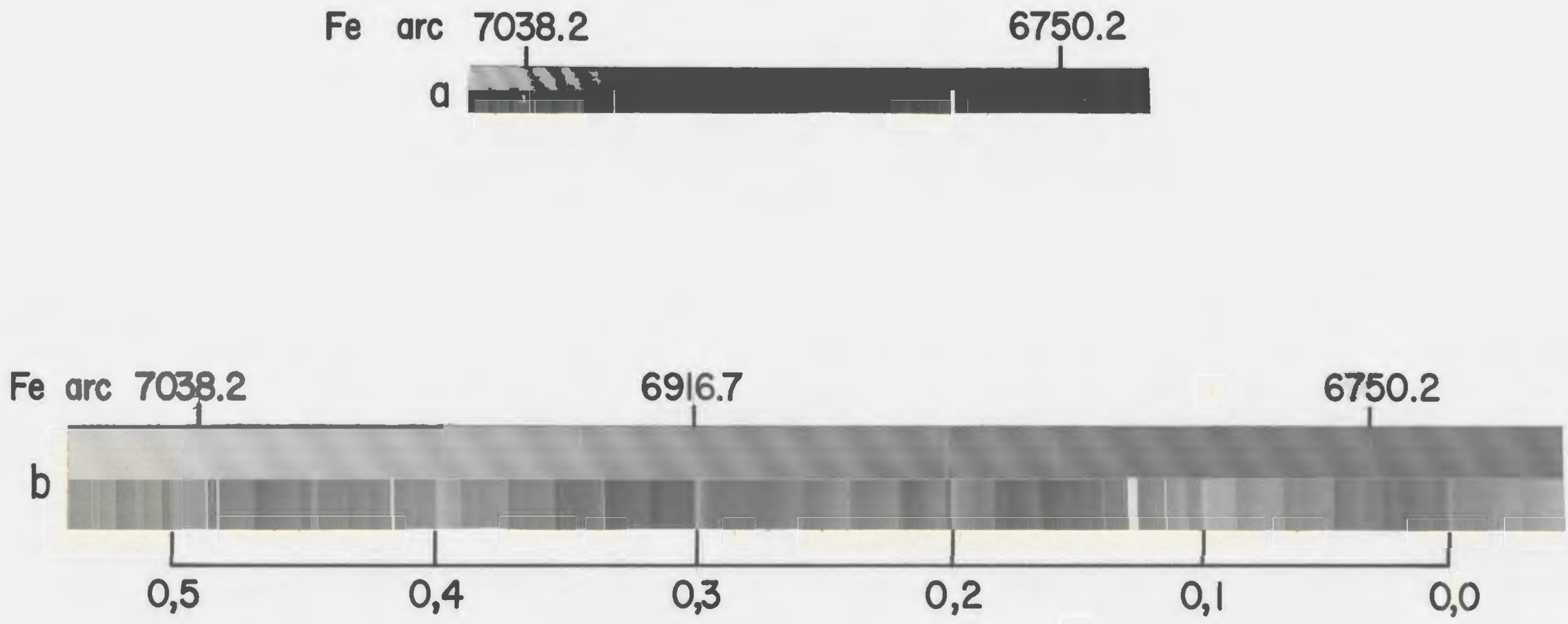
(2)

$$
\begin{aligned}
v= & 11869.5+107.0\left(v^{\prime}+\frac{1}{2}\right)-0.2\left(v^{\prime}+\frac{1}{2}\right)^{2} \\
& -\left[132.3\left(v^{\prime \prime}+\frac{1}{2}\right)-0.6\left(v^{\prime \prime}+\frac{y^{2}}{2}\right)^{2}\right] .
\end{aligned}
$$

As a check on the calculations and on the assignments of $v^{\prime}$ and $v^{\prime \prime}$, the wave numbers of all the bands were calculated by means of eq. (2). The last column of Table I gives the differences of the observed and calculated values. Except for three bands, these differences were less than $1 \mathrm{~cm}^{-1}$. The measurements of these three bands are considered to be less accurate. Since the lower state vibrational frequency $\left(132.3 \mathrm{~cm}^{-1}\right)$ of this system agrees very closely with the upper state frequency $\left(132.571 \mathrm{~cm}^{-1}\right.$ ) of the $B$ - $X$ system (see section 3.5 ), it is concluded that the lower state of the G - B system is the upper state of the B - X system.

\subsection{The $H \rightarrow B$ System:}

The H - B system consists of a single progression of 6 sharp bands degraded to shorter wave lengths. The spectrograms of this system are shown in plate II where strip a is a contact spectrogram and strip $b$ is an enlarged spectrogram. The wave lengths of a few iron arc lines are marked for comparison. The wave lengths, vacuum wave numbers and visual estimates of intensities of the bands are listed in Table III. The vibrational scheme is presented in Table IV and the values of the vibrational quantum numbers are included in Table III. The 0,4 and 0,1 bands of this system show anomalous 


\section{TABLE III}

Band Heads of the H-B System in the Region $\lambda 7050-6730 \AA$ *

\begin{tabular}{llll}
\hline$\lambda_{\text {air }}(\AA)$ & $v_{\text {vac }}$ & Intensity & $v ! v^{\prime \prime}$ \\
\hline 7044.45 & 14191.7 & $\mathrm{~m}$ & 0,5 \\
6980.55 & 14321.6 & $\mathrm{~s}$ & 0,4 \\
6916.91 & 14453.3 & $\mathrm{~s}$ & 0,3 \\
6854.03 & 14585.9 & $\mathrm{~s}$ & 0,2 \\
6792.07 & 14719.0 & $\mathrm{~s}$ & 0,1 \\
6731.45 & 14851.6 & $\mathrm{~m}$ & 0,0 \\
\end{tabular}

* The notation for the intensities is the same as the one given in Table I. 
TABLE IV

Vibrational Scheme of the H-B System

\begin{tabular}{|c|c|c|c|c|c|c|c|c|c|c|c|}
\hline $\begin{array}{c}v^{\prime \prime} \\
v^{\prime}\end{array}$ & 0 & & 1 & & 2 & & 3 & & 4 & & 5 \\
\hline 0 & 14851.6 & 132.6 & 14719.0 & 133.1 & 14585.9 & 132.6 & 14453.3 & 131.7 & 14321.6 & 129.9 & 14191.7 \\
\hline$\Delta G_{v+\frac{1}{2}}^{\prime \prime}$ & & 132.6 & & 133.1 & & 132.6 & & 131.7 & & 129.9 & \\
\hline
\end{tabular}


(a: contact spectrogram; b: enlarged spectrogram. Both $\mathrm{Fe}$ arc and $\mathrm{Bi}_{2}$ spectra are photographed in the first order of the grating. Bands degraded to longer wavelengths belong to the $B \rightarrow X$ system. )
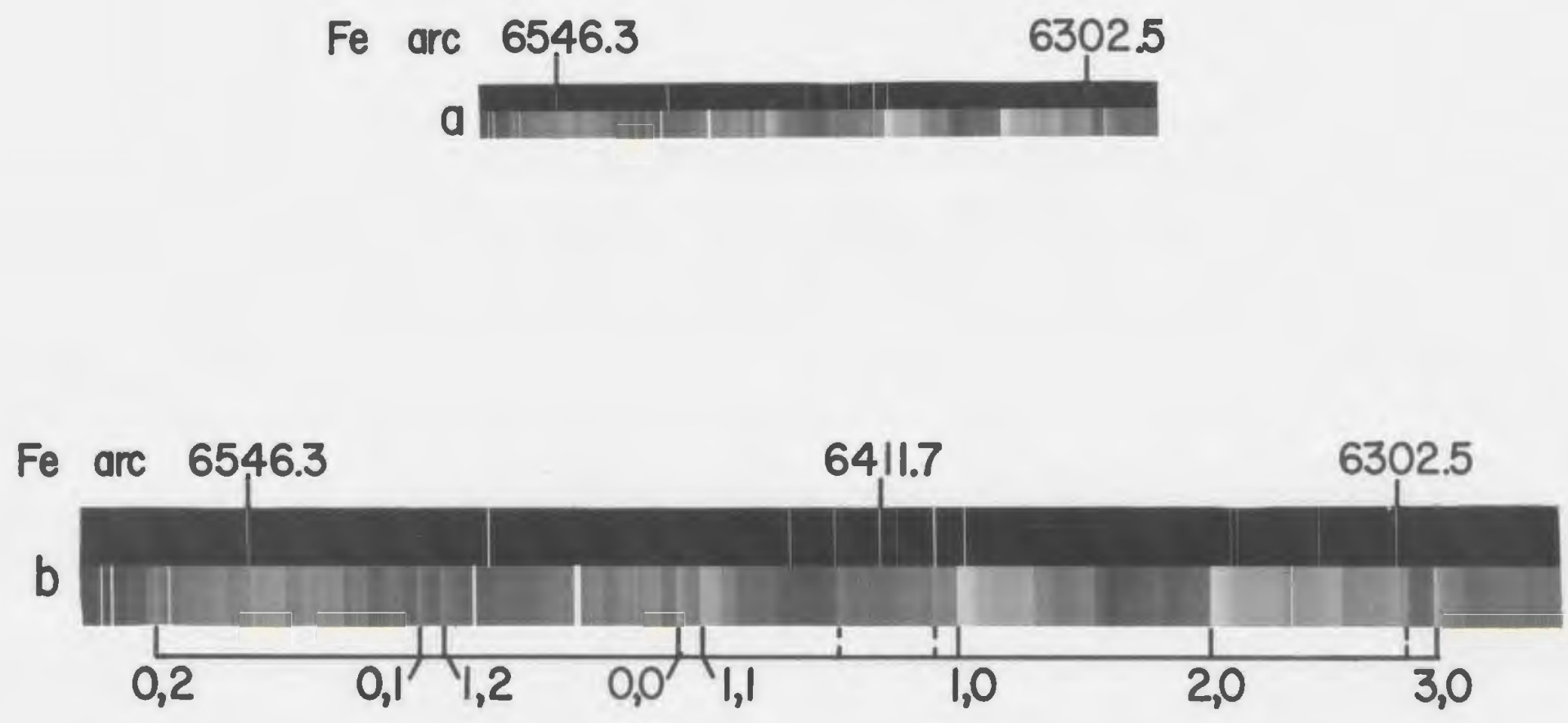
intensities because each of them is superposedc: by a band of the $B-X$ system, degraded toward longer wave lengths. The vibrational constants of the upper state of this system could not be determined since all the six bands of this system belong to a single v"-progression. The constants of the lower state were obtained by a least squares straight line fit of $\Delta G_{v}^{\prime \prime}+\frac{1}{2}$ versus $v+\frac{1}{2}($ Fig. 7$)$. The slope and intercept thus obtained were used to calculate $\omega_{e}^{\prime \prime} x_{e}^{\prime \prime}$ and $\omega_{e}^{\prime \prime}$. The values of the constants of this system are

$$
\begin{aligned}
& v_{00}=14851.6 \mathrm{~cm}^{-1} \\
& \omega_{e}^{\prime \prime}=134.0 \mathrm{~cm}^{-1} \\
& \omega_{e}^{\prime \prime} x_{e}^{\prime \prime}=0.34 \mathrm{~cm}^{-1}
\end{aligned}
$$

We see here that the lower state vibrational constants of this system agree closely with the upper state constants of the B - X system (see section 3.5). It is therefore inferred that the lower state of this system is the upper state of the $B$ - $X$ system.

\subsection{The I $\rightarrow$ B System:}

The I - B system consists of over 10 sharp bands which are degraded to shorter wave lengths. As can be seen from strip a or b of plate III, two of the bands $(1,1$ and 1,0$)$ of this system are superposed by bands of the $B-X$ system which are degraded toward longer wave lengths. The wave lengths, vacuum wave numbers and intensities of the bands are listed in Table $V$ and the vibrational scheme is displayed in 


\section{TABLE V}

Band Heads of the I-B System in the Region $\lambda 6570-6295 \AA$ *

\begin{tabular}{|c|c|c|c|c|c|}
\hline$\lambda_{\text {aix }}(\AA)$ & $v_{\text {vae }}\left(\mathrm{cm}^{-1}\right)$ & Intensity & $v !$ & $v^{\prime \prime}$ & $v_{\text {obs }}{ }^{-v_{c a l c}}$ \\
\hline 6566.25 & 15225.2 & m & 0 & 2 & 0.3 \\
\hline 6510.23 & 15356.2 & m & 0 & 1 & 0.1 \\
\hline 6505.22 & 15368.0 & $m$ & 1 & 2 & -1.1 \\
\hline 6455.11 & 15487.3 & m & 0 & 0 & -0.6 \\
\hline 6449.91 & 15499.8 & vs & 1 & 1 & -0.5 \\
\hline 6420.67 & 15570.4 & m & - & - & - \\
\hline 6400.54 & 15619.4 & $w$ & - & - & - \\
\hline 6395.18 & 15632.5 & vs & 1 & 0 & 0.4 \\
\hline 6341.32 & 15765.2 & vs & 2, & 0 & 1.1 \\
\hline 6300.18 & 15868.2 & $w$ & - & - & - \\
\hline 6293.63 & 15884.7 & m & 3, & 0 & 0.8 \\
\hline
\end{tabular}

* The notation for the intensities is the same as the one given in Table I . 
TABLE VI

Vibrational Scheme of the I-B System

\begin{tabular}{|c|c|c|c|c|c|c|}
\hline$v^{\prime \prime}$ & 0 & & 1 & & 2 & Mean $\Delta G_{v+\frac{1}{2}}^{\prime}$ \\
\hline \multirow[t]{2}{*}{0} & 15487.3 & 131.1 & 15356.2 & 131.0 & 15225.2 & \\
\hline & 145.2 & & 143.6 & & 142.8 & 143.9 \\
\hline \multirow[t]{2}{*}{1} & 15632.5 & 132.7 & 15499.8 & 131.8 & 15368.0 & \\
\hline & 132.7 & & & & & 132.7 \\
\hline \multirow[t]{2}{*}{2} & 15765.2 & & & & & \\
\hline & 119.5 & & & & & 119.5 \\
\hline 3 & 15884.7 & & & & & \\
\hline $\begin{array}{c}\text { Mean } \\
\Delta G_{v+\frac{1}{2}}^{\prime \prime}\end{array}$ & & 131.9 & & 131.4 & & \\
\hline
\end{tabular}




\section{THE $B \rightarrow X$ SYSTEM OF DIATOMIC BISMUTH}

(contact spectograms $a, b$ and $c$ : first order; $d, e, f, g$ and $h$ : second order.)

Fe $\operatorname{arc} 7967.9$

$a$ enena

Fe arc 75 II.I

b

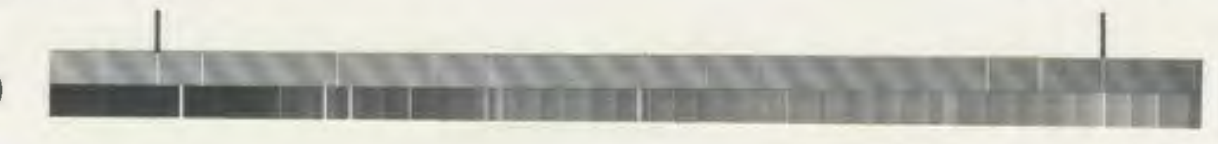

Fe arc 7090.4

c

.

6678.0 7595.0

PLATE IV 
Table VI. The method of obtaining the vibrational constants of the upper and lower states of this system is essentially the same as the one described for the $G$ - B system (section 3.2). The least squares straight line fits of $\Delta G_{v}+\frac{1}{2}$ versus $v+\frac{1}{2}$ for the upper and lower states of this system are also shown in Fig. 7. Finally, frequencies of the band heads of this system are represented by the expression

$$
\begin{aligned}
v= & 15477.4+156.4\left(v^{\prime}+\frac{1}{2}\right)-6.1\left(v^{\prime}+\frac{1}{2}\right)^{2} \\
& -\left[132.4\left(v^{\prime \prime}+\frac{1}{2}\right)-0.3\left(v^{\prime \prime}+\frac{1}{2}\right)^{2}\right] .
\end{aligned}
$$

The differences between the observed frequencies and the calculated frequencies (using eq. (3)) are listed in Table $v$. The values of $v^{\prime}$ and $v^{\prime \prime}$ are also included in the same Table. A glance at this table indicates that the differences, $v_{\text {obs }}{ }^{-v_{c a}}$, are $₹ 1 \mathrm{~cm}^{-1}$. Such a good agreement between the observed and calculated values of v's is a proof of the correctness of the vibrational assignments and the calculations. It is apparent from the values of the lower state vibrational constants of this system that this system and the $G-B$ and $H-B$ systems have $a$ common lower state which is the upper state of the B - X system.

\subsection{The $B \rightarrow X$ System:}

The emission bands of the extensive $B-X$ system which were previously studied by earlier workers in absorption occur in the spectral region from about $8000 \AA$ to $4830 \AA$. The contact spectrograms of this system are given in plate IV and the enlarged spectrograms are 
First order spectrograms
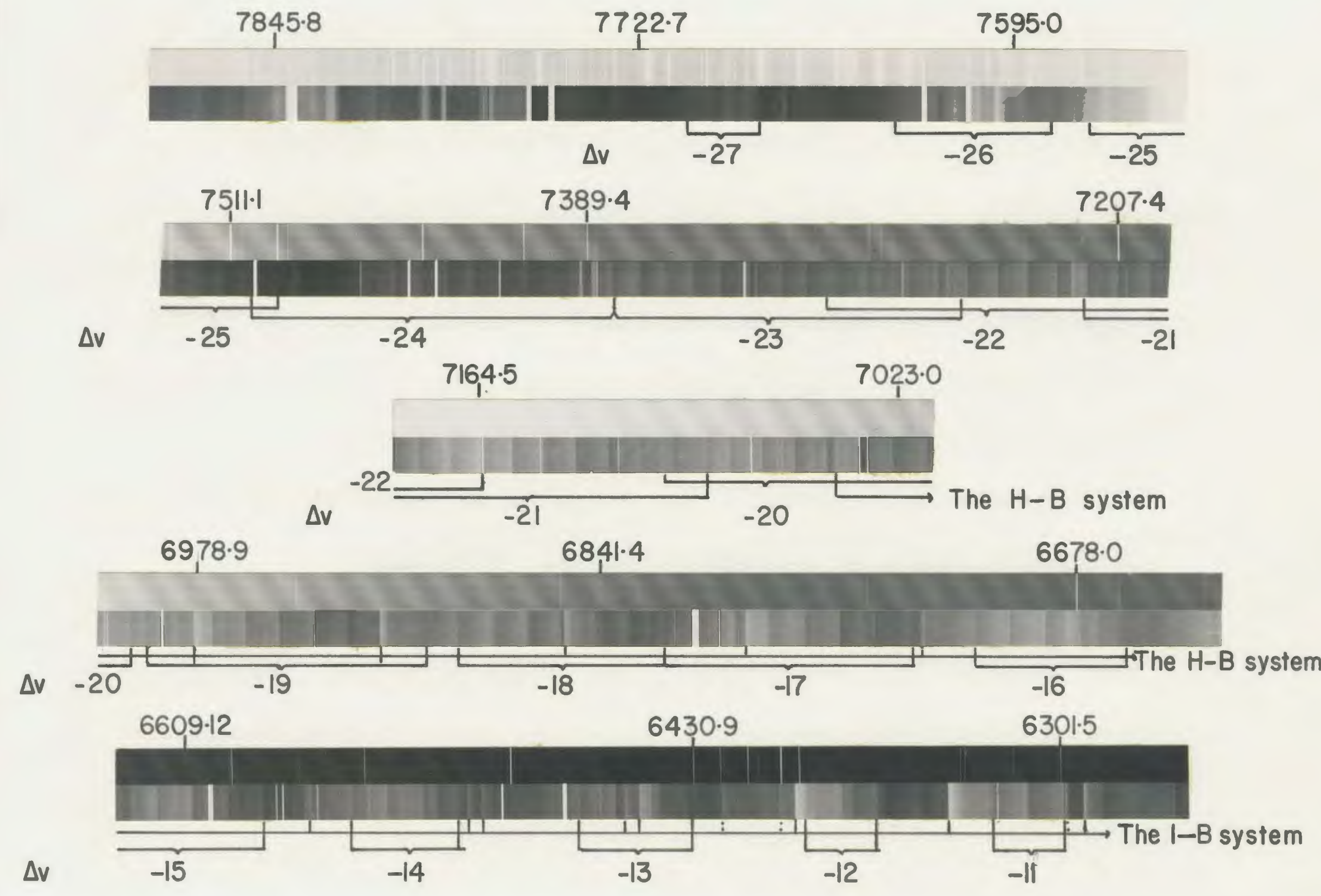
THE $B \rightarrow X$ SYSTEM OF DIATOMIC BISMUTH

PLATE VI Second order spectrograms

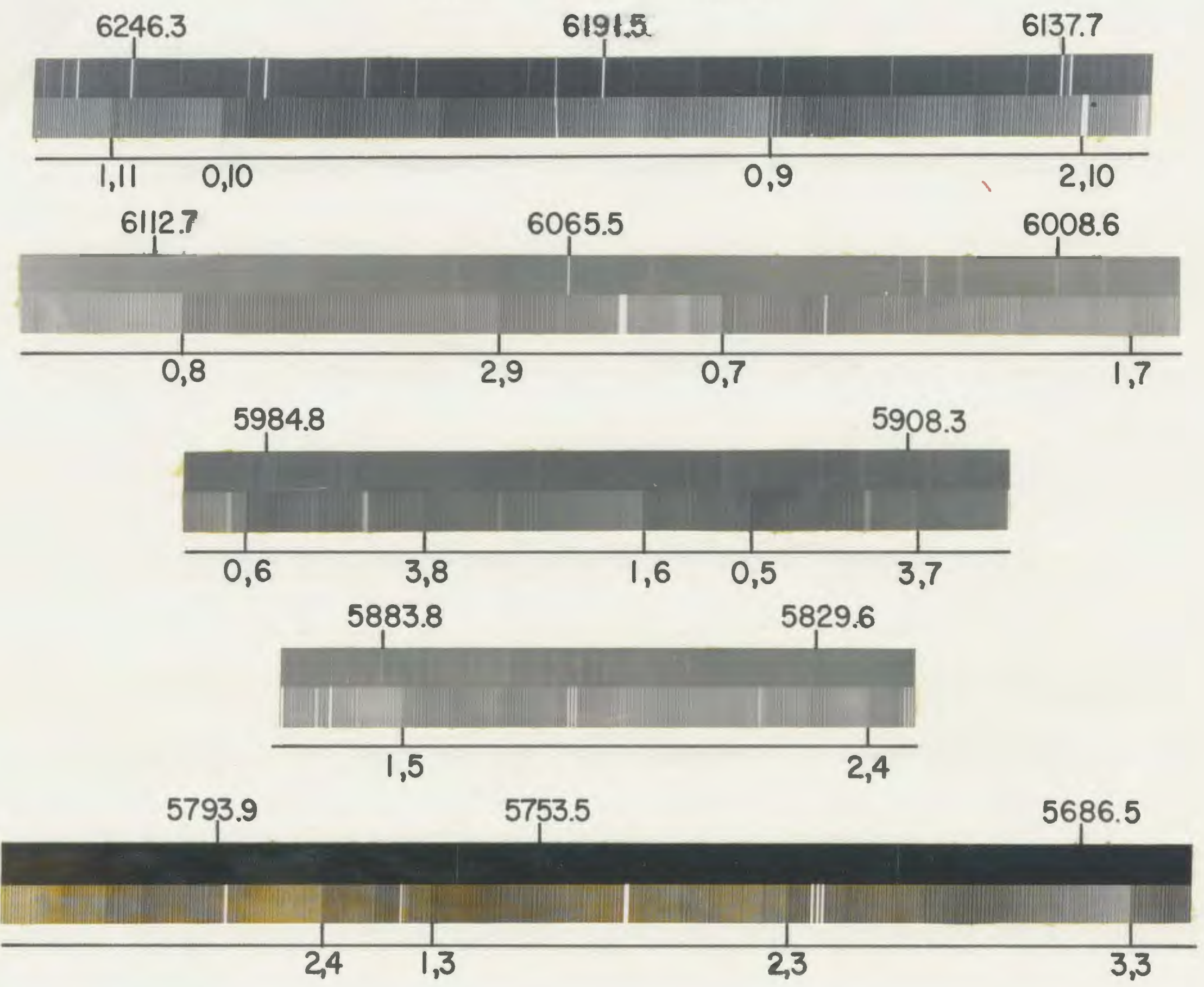




\section{Second order spectrograms}
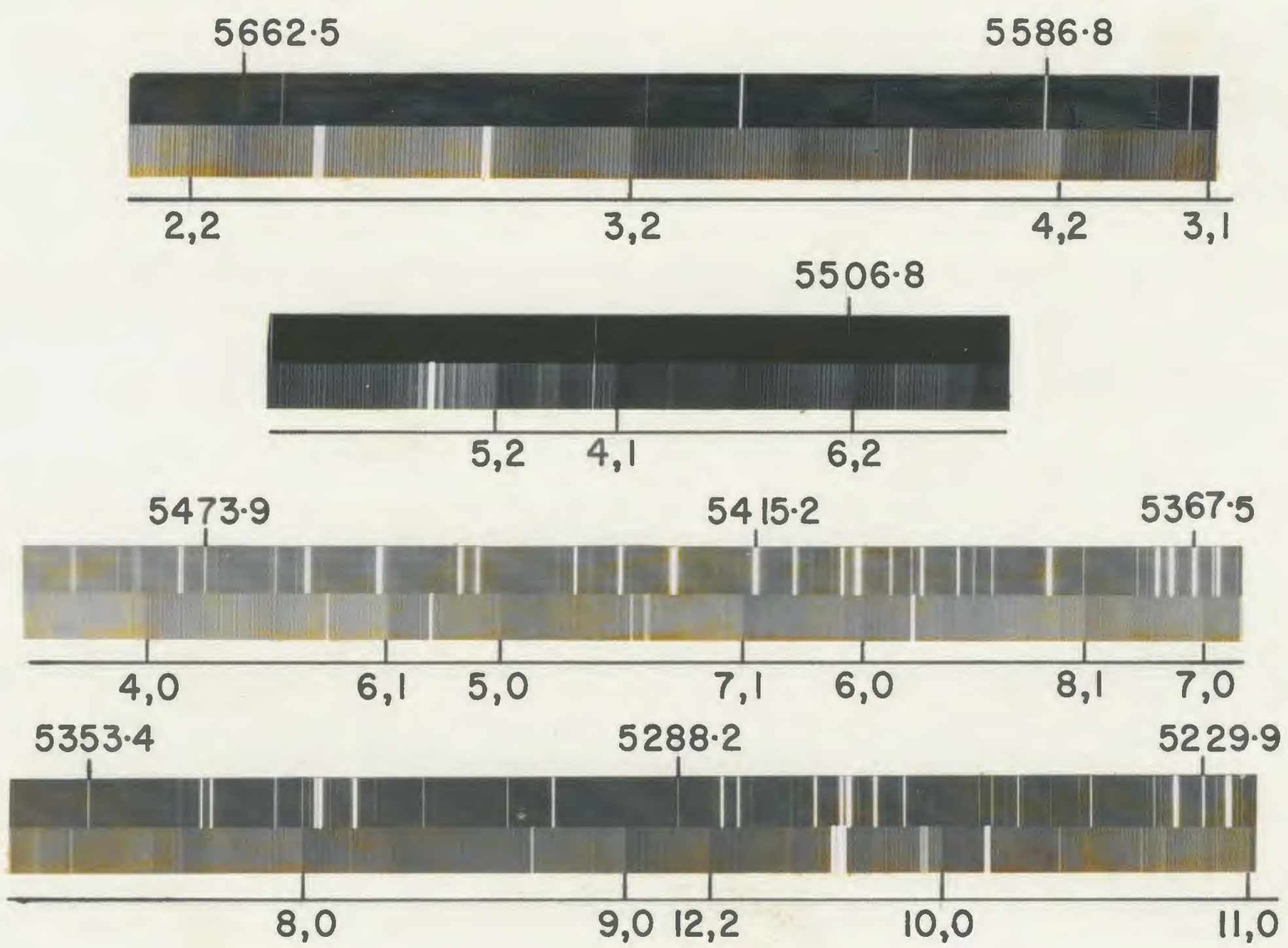
THE $B \rightarrow X$ SYSTEM OF DIATOMIC BISMUTH

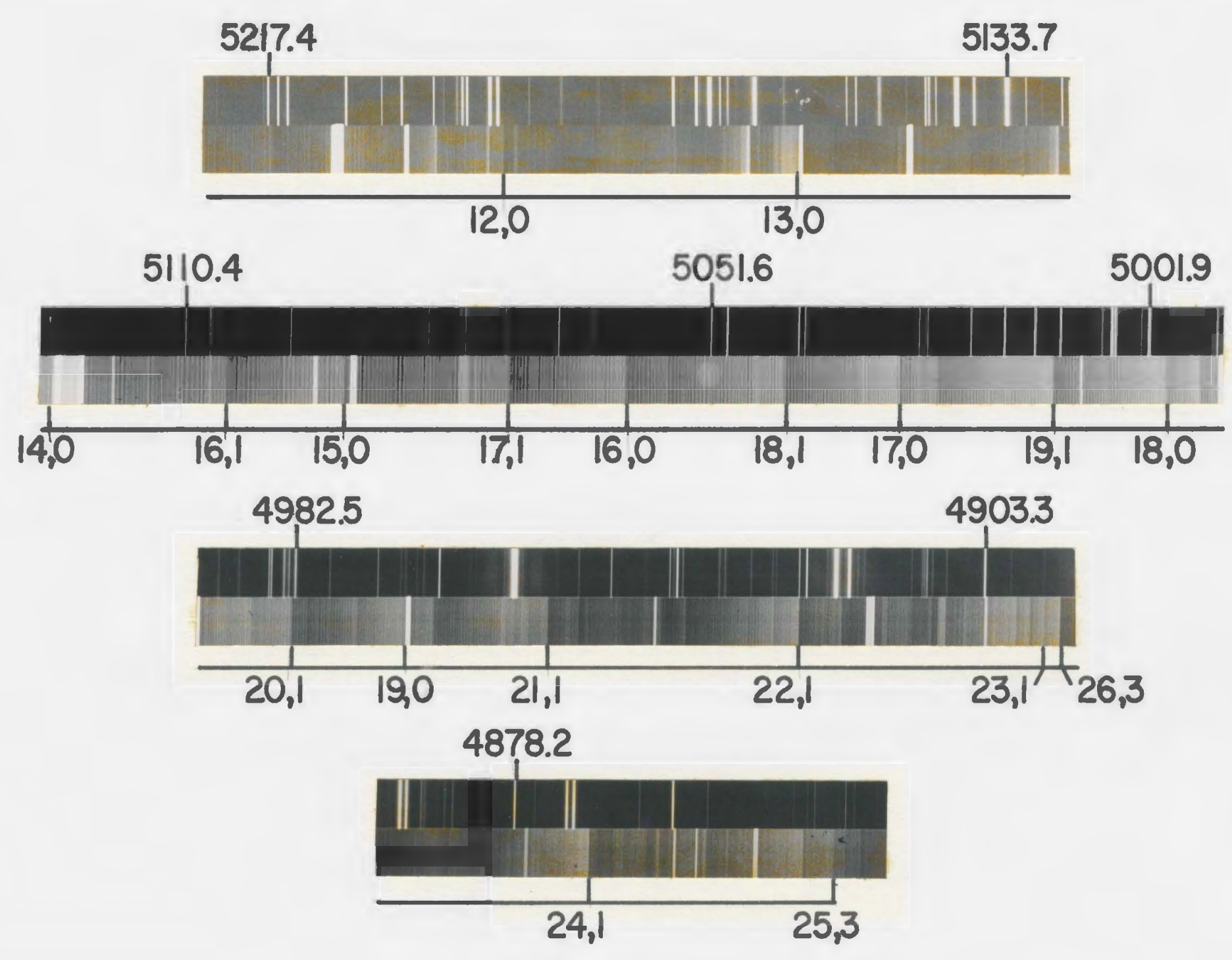


given in plates $V$ to VIII. Altogether, about 270 bands which are degraded toward longer wave lengths were measured in the above spectral region. The wave lengths, vacuum wave numbers and intensities of the bands are listed in Table VII. The emission data are in general agreement with the data obtained in absorption. The intensity estimates of the bands of this system are not of much significance except in a narrow spectral region because three types of plates were used to photograph different parts of this system. It was not attempted in the present work to compare the intensities in widely different regions. The vibrational scheme extending to $v^{\prime}=28$ and $v^{\prime \prime}=51$ is shown in Table VII which spreads over six pages in this thesis. The bands fall into the usual parabola. The fact that the width of each branch of the parabola is quite small agrees with the Franck-Condon principle that the internuclear distance does not change much in a transition. The mean values of the vibrational intervals $\Delta G_{v}+\frac{3}{2}$ of about 210 discrete bands of this system are plotted against $v+\frac{1}{2}$ in Fig. 7. A fourth order polynomial fit (see eq. 6, Appendix) was found to be necessary to obtain a smooth relation between the values of $\Delta G_{v}+\frac{3}{2}$ and the corresponding values of $v+\frac{1}{2}$ for the upper as well as the lower states of this system. The constants $b, c, d, e$, and $f$ in eq. 6 , Appendix, obtained from this fit were used to calculate the vibrational constants of this system using eq. 8 , Appendix. The value of $v_{e}$ was obtained as described in section 3.2 using frequencies of the abovementioned 210 bands. The following expression is derived from the frequencies of the band heads: 


$$
\begin{aligned}
v= & 17739.5+132.571\left(v^{\prime}+\frac{1}{2}\right)-0.3271\left(v^{\prime}+\frac{1}{2}\right)^{2} \\
& +0.5240 \times 10^{-3}\left(v^{\prime}+\frac{1}{2}\right)^{3}-0.5324 \times 10^{-4}\left(v^{\prime}+\frac{1}{2}\right)^{4} \\
& +0.154 \times 10^{-5}\left(v^{\prime}+\frac{1}{2}\right)^{5} \\
& -\left[173.132\left(v^{\prime \prime}+\frac{1}{2}\right)-0.4156\left(v^{\prime \prime}+\frac{1}{2}\right)^{2}\right. \\
& +0.2437 \times 10^{-2}\left(v^{\prime \prime}+\frac{1}{2}\right)^{3}-0.8356 \times 10^{-4}\left(v^{\prime \prime}+\frac{1}{2}\right)^{4} \\
& \left.+0.72 \times 10^{-6}\left(v^{\prime \prime}+\frac{1}{2}\right)^{5}\right] \cdot
\end{aligned}
$$

The vibrational assignments $v^{\prime}, v^{\prime \prime}$ and the differences $\left(v_{\text {obs }}{ }^{-v_{\text {cal }}}\right.$ ) are also included in Table VII. For at least $85 \%$ of the band heads of this system, these differences are less than $1 \mathrm{~cm}^{-1}$. It is claimed that the vibrational constants obtained for the $B$ - $X$ system in the present work are the most accurate avallable so far for this system.

In conclusion of this chapter, it may be necessary to comment briefly on the values of $\omega_{e}$ and $\omega_{e} x_{e}$ of state $B$ obtained independently from the analyses of the four different band systems described here. A comparison of these values indicate that all the values of $\omega_{e}$ agree we $h$ with each other; the values of $\omega_{e} x_{e}$ also agree well with each other, except the one obtained for the G-B system $\left(\omega_{e}^{\prime \prime} x_{e}^{\prime \prime}=0.6 \mathrm{~cm}^{-1}\right)$. This apparently larger value of $\omega_{e}^{\prime \prime} x_{e}^{\prime \prime}$ may be due to uncertainty in the measurement of the band heads. 


\section{TABLE VII}

Band Heads of the B-X System in the Region $\lambda 7980-4830 \AA$ *

\begin{tabular}{|c|c|c|c|c|c|}
\hline$\lambda_{\text {air }}(\AA)$ & $v_{\operatorname{vac}}\left(\mathrm{cm}^{-1}\right)$ & Intensity & $v !$ & $v^{\prime \prime}$ & $\nu_{\text {obs }}{ }^{-\nu}$ celc \\
\hline 7971.70 & 12540.9 & m & - & - & - \\
\hline 7968.77 & 12545.5 & w & - & - & - \\
\hline 7952.47 & 12571.3 & $w$ & - & - & - \\
\hline 7908.17 & 12641.7 & m & - & - & - \\
\hline 7889.62 & 12671.4 & $m$ & - & - & - \\
\hline 7844.40 & 12744.5 & s & - & - & - \\
\hline 7835.54 & 12758.9 & $m$ & - & - & - \\
\hline 7812.15 & 12797.1 & w & - & - & - \\
\hline 7795.18 & 12824.9 & $\mathbf{s}$ & - & - & - \\
\hline 7744.30 & 12909.2 & $w$ & - & - & - \\
\hline 7707.23 & 12971.3 & w & 24, & & -1.9 \\
\hline 7699.27 & 12984.7 & vw & 23, & 50 & -0.9 \\
\hline 7690.88 & 12998.8 & w & 22 , & 49 & 0.5 \\
\hline 7684.10 & 13010.3 & $w$ & 21 , & 48 & -0.9 \\
\hline 7656.25 & 13057.6 & $w w$ & - & - & - \\
\hline
\end{tabular}


TABLE VII (Continued)

Band Heads of the B-X System

\begin{tabular}{|c|c|c|c|c|}
\hline$\lambda_{\text {air }}(\AA)$ & $v_{v e c}\left(\mathrm{~cm}^{-1}\right)$ & Intensity & $v ! v^{\prime \prime}$ & $\nu_{\mathrm{obs}}{ }^{-} \nu_{\mathrm{calc}}$ \\
\hline 7635.67 & 13092.8 & $w$ & 25,51 & 2.7 \\
\hline 7629.81 & 13102.9 & $w$ & 24,50 & -0.1 \\
\hline 7621.69 & 13116.9 & $m$ & 23,49 & 0.7 \\
\hline 7614.61 & 13129.0 & s & 22,48 & -0.7 \\
\hline 7606.57 & 13142.9 & s & 21,47 & -0.5 \\
\hline 7598.35 & 13157.1 & s & 20,46 & -0.3 \\
\hline 7590.14 & 13171.4 & $m$ & 19,45 & -0.3 \\
\hline 7582.02 & 13185.5 & w & 18,44 & -0.8 \\
\hline 7569.73 & 13206.9 & w & 26,51 & 0.4 \\
\hline 7562.11 & 13220.2 & m & 25,50 & 0.3 \\
\hline 7554.40 & 13233.7 & $w$ & 24,49 & 0.1 \\
\hline 7546.25 & 13248.0 & $w$ & 23,48 & 0.4 \\
\hline 7538.77 & 13261.1 & s & 22,47 & -0.8 \\
\hline 7530.70 & 13275.3 & s & 21,46 & -1.2 \\
\hline 7522.30 & 13290.2 & s & 20,45 & -1.2 \\
\hline 7513.77 & 13305.2 & $\mathbf{s}$ & $\begin{array}{r}19,44 \\
(18,43\end{array}$ & $\begin{array}{r}-1.4 \\
0.2\end{array}$ \\
\hline 7504.14 & 13322.3 & m & & -0.2 \\
\hline
\end{tabular}


TABLE VII (Continued)

Band Heads of the B-X System

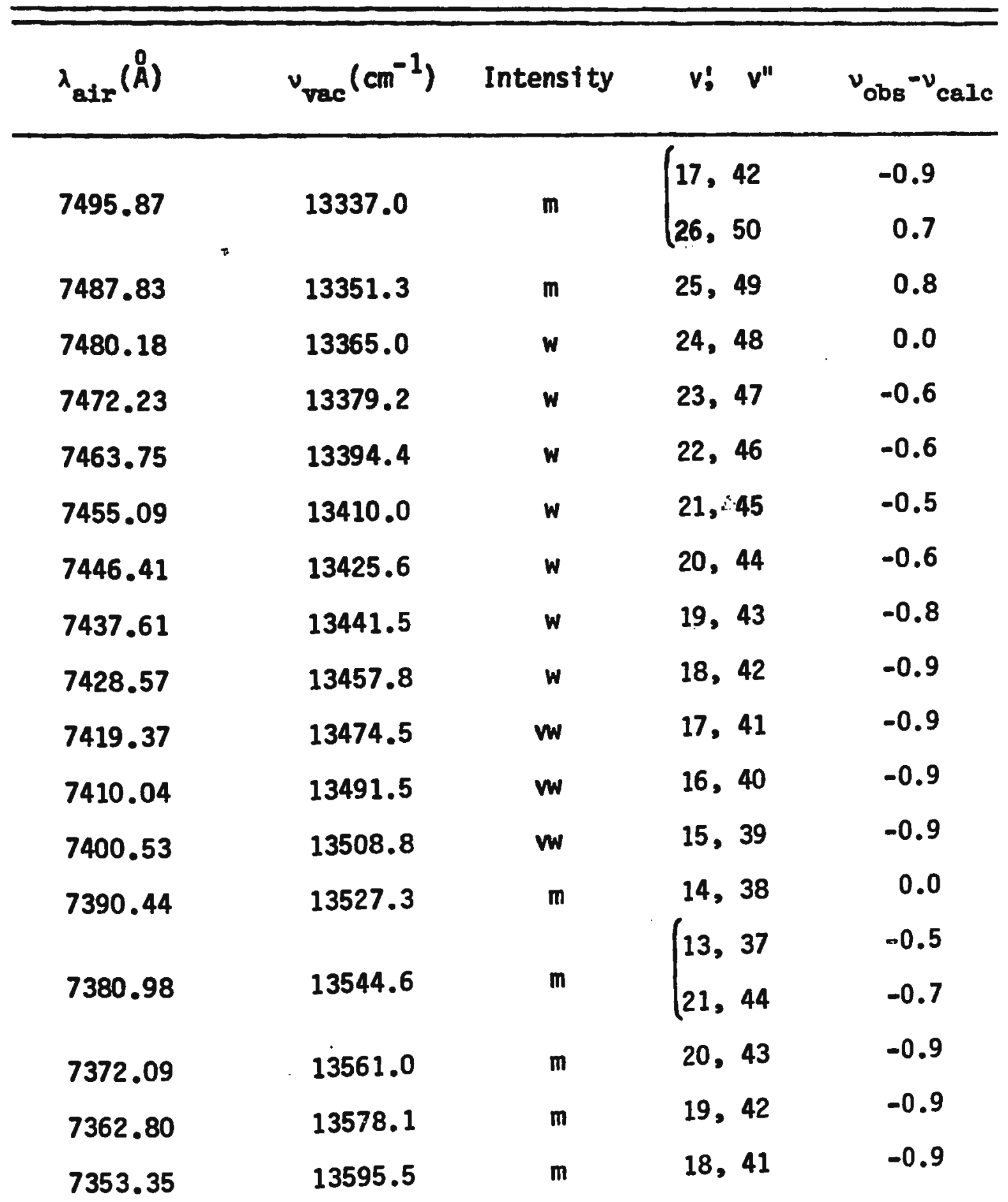


TABLE VII (Continued)

Band Heads of the B - X System

\begin{tabular}{|c|c|c|c|c|}
\hline$\lambda_{\text {air }}(\AA)$ & $v_{\operatorname{vac}}\left(\mathrm{cm}^{-1}\right)$ & Intensity & $v ! v^{\prime \prime}$ & $v_{\text {obs }}{ }^{-v_{c a l c}}$ \\
\hline 7343.84 & 13613.1 & $m$ & 17,40 & -0.8 \\
\hline 7334.07 & 13631.3 & $w$ & 16,39 & -0.5 \\
\hline 7324.26 & 13649.5 & $m$ & 15,38 & -0.5 \\
\hline 7314.47 & 13667.8 & $m$ & 14,37 & -0.7 \\
\hline 7308.37 & 13679.2 & $w$ & 21,43 & -1.8 \\
\hline 7304.34 & 13686.7 & m & 13,36 & -0.6 \\
\hline 7298.48 & 13697.7 & $w$ & 20,42 & -1.1 \\
\hline 7294.37 & 13705.4 & m & 12,35 & -0.9 \\
\hline 7289.00 & 13715.5 & m & 19,41 & -1.2 \\
\hline 7284.48 & 13724.0 & m & 11,34 & -1.5 \\
\hline 7279.17 & 13734.1 & $m$ & 18,40 & -0.9 \\
\hline 7273.64 & 13744.5 & w & 10,33 & -0.9 \\
\hline 7269.28 & 13752.7 & $m$ & 17,39 & -0.6 \\
\hline 7265.80 & 13759.3 & $m$ & - & - \\
\hline 7262.71 & 13765.2 & m & 9,32 & 0.0 \\
\hline 7259.36 & 13771.5 & m & 16,38 & -0.6 \\
\hline 7249.30 & 13790.6 & $\mathbf{s}$ & 15,37 & -0.7 \\
\hline 7239.02 & 13810.2 & $\mathbf{s}$ & 14,36 & -0.5 \\
\hline 7228.78 & 13829.8 & $\mathbf{s}$ & 13,35 & -0.6 \\
\hline 7218.32 & 13849.8 & $\mathbf{s}$ & 12,34 & -0.6 \\
\hline 7207.71 & 13870.2 & m & 11,33 & -0.5 \\
\hline
\end{tabular}


TABLE VII (Continued)

Band Heads of the B-X System

\begin{tabular}{|c|c|c|c|c|}
\hline$\lambda_{\text {air }}(\AA)$ & $v_{\operatorname{vac}}\left(\mathrm{cm}^{-1}\right)$ & Intensity & $v^{\prime} \quad v^{\prime \prime}$ & $v_{\text {obs }}{ }^{-v_{c a l c}}$ \\
\hline 7197.09 & 13890.7 & $\mathbf{m}$ & $\begin{cases}17, & 38 \\
10, & 32\end{cases}$ & $\begin{array}{l}-2.9 \\
-0.5\end{array}$ \\
\hline 7185.74 & 13912.6 & m & $\left(\begin{array}{r}16,37 \\
9,31\end{array}\right.$ & $\begin{array}{r}-0.8 \\
0.6\end{array}$ \\
\hline 7175.15 & 13933.2 & $\mathbf{s}$ & $\left(\begin{array}{r}15,36 \\
8,30\end{array}\right.$ & $\begin{array}{r}-0.3 \\
0.2\end{array}$ \\
\hline 7164.64 & 13953.6 & $s^{* \star}$ & $\left(\begin{array}{c}14,35 \\
7,29\end{array}\right.$ & $\begin{array}{l}-0.2 \\
-0.7\end{array}$ \\
\hline 7153.98 & 13974.4 & $\mathbf{s}$ & 13,34 & -0.1 \\
\hline 7143.29 & 13995.3 & $m^{\star \star}$ & 12,33 & -0.1 \\
\hline 7132.48 & 14016.5 & m & 11,32 & -0.1 \\
\hline 7121.58 & 14038.0 & m & 10,31 & 0.0 \\
\hline 7110.52 & 14059.8 & w & 9,30 & 0.1 \\
\hline 7102.14 & 14076.4 & w & 15,35 & -0.2 \\
\hline 7099.37 & 14081.9 & $w$ & 8,29 & 0.2 \\
\hline 7091.10 & 14098.5 & $w$ & 14,34 & 0.6 \\
\hline 7088.34 & 14103.8 & $w$ & 7,28 & -0.1 \\
\hline 7080.38 & 14119.7 & m & 13,33 & 0.2 \\
\hline 7069.52 & 14141.3 & m & 12,32 & 0.0 \\
\hline 7058.52 & 14163.4 & $m$ & 11,31 & 0.0 \\
\hline
\end{tabular}




\section{TABLE VII (Continued)}

Band Heads of the B-X System

\begin{tabular}{|c|c|c|c|c|}
\hline$\lambda_{\text {air }}(\AA)$ & $v_{v a c}\left(\mathrm{~cm}^{-1}\right)$ & Intensity & $v ! \quad v^{\prime \prime}$ & $v_{\mathrm{obs}}{ }^{-v_{c a l c}}$ \\
\hline 7047.35 & 14185.8 & m & 10,30 & 0.0 \\
\hline 7036.10 & 14208.5 & $m$ & 9,29 & 0.1 \\
\hline 7024.90 & 14231.2 & $\mathbf{m}$ & 8,28 & -0.1 \\
\hline 7013.62 & 14254.1 & $\mathbf{m}$ & 7,27 & -0.3 \\
\hline 6986.18 & 14310.0 & $m$ & 11,30 & -1.2 \\
\hline 6974.24 & 14334.5 & m & 10,29 & 0.1 \\
\hline 6970.13 & 14343.0 & $w$ & $-\quad-$ & - \\
\hline 6962.85 & 14358.0 & $m$ & 9,28 & 0.0 \\
\hline 6951.43 & 14381.6 & $m$ & 8,27 & 0.1 \\
\hline 6939.91 & 14405.4 & $m$ & 7,26 & -0.3 \\
\hline 6928.13 & 14429.9 & m & 6,25 & -0.1 \\
\hline 6916.36 & 14454.5 & m & 5,24 & 0.4 \\
\hline 6890.59 & 14508.6 & m & 9,27 & 0.2 \\
\hline 6878.97 & 14533.1 & $\mathbf{s}$ & 8,26 & 0.0 \\
\hline 6867.27 & 14557.8 & s & 7,25 & -0.2 \\
\hline 6855.49 & 14582.8 & m & 6,24 & -0.3 \\
\hline 6843.49 & 14608.4 & m & 5,23 & 0.1 \\
\hline 6831.54 & 14634.0 & m & 4,22 & 0.1 \\
\hline 6824.87 & 14648.3 & $w$ & $-\quad-$ & - \\
\hline
\end{tabular}




\section{TABLE VII (Continued)}

Band Heads of the B-X System

\begin{tabular}{|c|c|c|c|c|}
\hline$\lambda_{\text {air }}(\stackrel{D}{A})$ & $v_{\operatorname{vac}}\left(\mathrm{cm}^{-1}\right)$ & Intensity & $v ! \quad v^{\prime \prime}$ & $v_{o b s}{ }^{-v} c a l c$ \\
\hline 6819.87 & 14659.0 & $w$ & $\left(\begin{array}{ll}3, & 21 \\
9, & 26\end{array}\right.$ & $\begin{array}{l}-0.6 \\
-0.8\end{array}$ \\
\hline 6795.93 & 14710.6 & $\mathbf{s}$ & 7,24 & -0.5 \\
\hline 6783.77 & 14737.0 & s & 6,23 & 0.0 \\
\hline 6772.07 & 14762.5 & s & 5,22 & -0.7 \\
\hline 6759.76 & 14789.4 & s & 4,21 & -0.1 \\
\hline 6751.53 & 14807.4 & $w$ & $-\quad-$ & - \\
\hline 6747.88 & 14815.4 & $m$ & $-\quad-$ & - \\
\hline 6747.45 & 14816.3 & $m$ & 3,20 & 0.2 \\
\hline 6743.26 & 14825.5 & $w$ & -- & - \\
\hline 6735.66 & 14842.3 & $w$ & 2,19 & -0.5 \\
\hline 6726.13 & 14863.3 & $w$ & 7,23 & -1.7 \\
\hline 6713.35 & 14891.6 & m & 6,22 & -0.2 \\
\hline 6701.34 & 14918.3 & $\mathbf{s}$ & 5,21 & -0.5 \\
\hline 6696.45 & 14929.2 & w & $-\quad-$ & - \\
\hline 6692.84 & 14937.2 & $m$ & -- & - \\
\hline 6689.04 & 14945.7 & s & 4,20 & -0.3 \\
\hline 6681.42 & 14962.8 & $\mathbf{s}$ & $-\quad-$ & - \\
\hline 6676.91 & 14972.9 & m & 3,19 & -0.5 \\
\hline 6671.07 & 14986.0 & $w$ & - & - \\
\hline
\end{tabular}


TABLE VII (Continued)

Band Heads of the B-X System

\begin{tabular}{|c|c|c|c|c|}
\hline$\lambda_{\text {air }}(\AA)$ & $v_{\text {vac }}\left(\mathrm{cm}^{-1}\right)$ & Intensity & $v ! v^{\prime \prime}$ & $v_{\text {obs }}{ }^{-v}$ calc \\
\hline 6664.56 & 15000.6 & $w$ & 2,18 & -0.3 \\
\hline 6631.93 & 15074.4 & $w$ & 5,20 & -1.0 \\
\hline 6619.50 & 15102.7 & s & 4,19 & -0.7 \\
\hline 6607.22 & 15130.8 & s & 3,18 & -0.8 \\
\hline 6594.85 & 15159.2 & m & 2,17 & -0.7 \\
\hline 6582.35 & 15188.0 & m & 1,16 & -0.4 \\
\hline 6550.98 & 15260.7 & $\mathbf{s}$ & 4,18 & -0.8 \\
\hline 6538.42 & 15290.0 & $\mathbf{s}$ & 3,17 & -0.5 \\
\hline 6526.07 & 15318.9 & $\mathbf{s}$ & 2,16 & -0.8 \\
\hline 6520.91 & 15331.1 & $m$ & $-\quad-$ & - \\
\hline 6513.47 & 15348.6 & $m$ & 1,15 & -0.4 \\
\hline 6470.85 & 15449.7 & s & 3,16 & -0.6 \\
\hline 6466.01 & 15461.2 & m & $-\quad-$ & - \\
\hline 6461.30 & 15472.5 & m & $-\quad-$ & - \\
\hline 6458.25 & 15479.8 & $\mathbf{s}$ & 2,15 & -0.5 \\
\hline 6445.48 & 15510.5 & $\mathbf{s}$ & 1,14 & 0.2 \\
\hline 6432.47 & 15541.8 & m & 0,13 & 1.2 \\
\hline 6391.48 & 15641.5 & m & 2,14 & -0.1 \\
\hline 6378.88 & 15672.4 & $\mathbf{s}$ & 1,13 & -0.1 \\
\hline
\end{tabular}




\section{TABLE VII (Continued)}

Band Heads of the B-X System

\begin{tabular}{|c|c|c|c|c|}
\hline$\lambda_{\text {aix }}(\AA)$ & $v_{v a c}\left(\mathrm{~cm}^{-1}\right)$ & Intensity & $v ! v^{\prime \prime}$ & $\nu_{\text {obs }}{ }^{-\nu}$ calc \\
\hline 6375.01 & 15681.9 & m & $-\quad-$ & - \\
\hline 6366.36 & 15703.2 & s & 0,12 & -0.3 \\
\hline 6363.95 & 15709.2 & $w$ & $-\quad-$ & - \\
\hline 6354.35 & 15732.9 & $w$ & $-\quad-$ & - \\
\hline 6337.61 & 15774.5 & $m$ & 3,14 & 2.3 \\
\hline 6325.18 & 15805.5 & m & 2,13 & 1.7 \\
\hline 6313.13 & 15835.6 & $m$ & 1,12 & 0.2 \\
\hline 6300.37 & 15867.7 & m & 0,11 & 0.5 \\
\hline 6286.55 & 15902.6 & $w$ & 4,14 & 0.4 \\
\hline 6273.30 & 15936.2 & $w$ & 3,13 & 1.8 \\
\hline 6861.51 & 15966.2 & $w$ & 2,12 & -0.5 \\
\hline 6248.69 & 15998.9 & $w$ & 1,11 & -0.2 \\
\hline 6235.74 & 16032.2 & m & 0,10 & 0.5 \\
\hline 6223.77 & 16063.0 & $w$ & 4,13 & -1.4 \\
\hline 6210.73 & 16096.7 & $w$ & 3,12 & -0.6 \\
\hline 6185.01 & 16163.7 & m & 1,10 & 0.1 \\
\hline 6172.11 & 16197.4 & $\mathbf{s}$ & 0,9 & 0.5 \\
\hline 6168.12 & 16207.9 & $w$ & -- & - \\
\hline 6163.37 & 16220.4 & $w$ & $-\quad-$ & - \\
\hline 6147.56 & 16262.1 & m & 3,11 & 1.1 \\
\hline
\end{tabular}




\section{TABLE VII (Continued)}

Band Heads of the B-X System

\begin{tabular}{|c|c|c|c|c|}
\hline$\lambda_{\text {air }}(\AA)$ & $v_{v e c}\left(\mathrm{~cm}^{-1}\right)$ & Intensity & $v ! v^{\prime \prime}$ & $v_{\text {obs }}{ }^{-v}$ calc \\
\hline 6135.57 & 16293.9 & $m^{\star \star}$ & 2,10 & -1.0 \\
\hline 6109.43 & 16363.6 & s & 0,8 & 0.6 \\
\hline 6073.59 & 16460.2 & m & 2,9 & 0.1 \\
\hline 6056.50 & 16506.6 & $w$ & $-\quad-$ & - \\
\hline 6051.69 & 16519.8 & s & 5,11 & -0.5 \\
\hline 6047.79 & 16530.4 & $m$ & 0,7 & 0.6 \\
\hline 6043.31 & 16542.7 & $w$ & $-\quad-$ & - \\
\hline 6038.62 & 16555.5 & w & 4,10 & 0.0 \\
\hline 6018.29 & 16611.4 & m & 7,12 & -1.9 \\
\hline 6012.86 & 16626.4 & m & 2,8 & 0.2 \\
\hline 6004.86 & 16648.6 & m & 6,11 & -0.4 \\
\hline 6000.00 & 16662.1 & $m$ & 1,7 & 0.4 \\
\hline 5994.94 & 16676.1 & $w$ & $-\quad-$ & - \\
\hline 5987.15 & 16697.8 & $m$ & 0,6 & 0.5 \\
\hline 5978.58 & 16721.8 & w & 4,9 & 1.1 \\
\hline 5966.11 & 16756.8 & $w$ & 3,8 & 0.0 \\
\hline 5953.26 & 16792.9 & w & 2,7 & -0.1 \\
\hline 5940.35 & 16829.4 & $m$ & 1,6 & 0.2 \\
\hline 5927.29 & 16866.5 & $w$ & 0,5 & 0.8 \\
\hline
\end{tabular}


TABLE VII (Continued)

Band Heads of the B-X System

\begin{tabular}{|c|c|c|c|c|c|}
\hline$\lambda_{\operatorname{air}}(\AA)$ & $v_{v a c}\left(\mathrm{~cm}^{-1}\right)$ & Intensity & $v !$ & $v^{\prime \prime}$ & $\nu_{\text {obs }}{ }^{-\nu_{c a l c}}$ \\
\hline 5907.34 & 16923.4 & $w$ & 3 , & 7 & -0.2 \\
\hline 5880.94 & 16999.4 & s & 1, & 5 & 1.8 \\
\hline 5869.16 & 17033.5 & $w$ & 0 & 4 & -1.3 \\
\hline 5862.45 & 17053.0 & $w$ & 4, & 7 & -0.5 \\
\hline 5837.43 & 17126.1 & m & - & - & - \\
\hline 5835.53 & 17131.7 & m & 2 & 5 & 2.8 \\
\hline 5831.03 & 17144.9 & $w$ & 6 & 8 & 0.2 \\
\hline 5823.39 & 17167.4 & m & 1 , & 4 & 0.7 \\
\hline 5804.99 & 17221.8 & $w$ & 4, & 6 & 0.7 \\
\hline 5779.33 & 17298.3 & m & 2 & 4 & 0.3 \\
\hline 5766.14 & 17337.8 & $w$ & 1 , & 3 & 1.2 \\
\hline 5761.54 & 17351.7 & w & 5 & 6 & 1.3 \\
\hline 5736.13 & 17428.5 & $w$ & 3 & 4 & -0.1 \\
\hline 5732.68 & 17439.0 & $w$ & 7 & 7 & -0.5 \\
\hline 5726.11 & 17459.0 & m & - & - & - \\
\hline 5723.19 & 17467.9 & m & 2 & 3 & 0.0 \\
\hline 5710.00 & 17508.2 & w & 1 & 2 & 0.9 \\
\hline 5705.90 & 17520.7 & $w$ & 5 & 5 & 1.9 \\
\hline 5680.59 & 17598.9 & m & 3, & 3 & 0.4 \\
\hline
\end{tabular}


TABLE VII (Continued)

Band Heads of the B-X System

\begin{tabular}{|c|c|c|c|c|c|}
\hline$\lambda_{\text {air }}(\stackrel{0}{A})$ & $v_{\text {vec }}\left(\mathrm{cm}^{-1}\right)$ & Intensity & $v$ : & $v^{\prime \prime}$ & $\nu_{\text {obs }}{ }^{-\nu} \nu_{\text {calc }}$ \\
\hline 5667.37 & 17640.0 & $w$ & 2 , & 2 & 1.4 \\
\hline 5649.15 & 17696.9 & $w$ & 9, & 7 & 3.3 \\
\hline 5637.25 & 17734.2 & $w$ & 8 & 6 & -0.3 \\
\hline 5626.07 & 17769.5 & $w$ & 3 & 2 & 0.3 \\
\hline 5607.80 & 17827.4 & $w$ & - & - & - \\
\hline 5601.87 & 17846.2 & w & - & - & - \\
\hline 5597.50 & 17860.3 & $w$ & 5 & 3 & 2.5 \\
\hline 5585.22 & 17899.4 & $m$ & 4, & 2 & 0.2 \\
\hline 5570.98 & 17945.2 & $w$ & 3 & 1 & 4.5 \\
\hline 5545.14 & 18028.8 & m & 5 , & 2 & 0.3 \\
\hline 5538.33 & 18051.0 & w & - & - & - \\
\hline 5531.88 & 18072.0 & $w$ & 4, & 1 & 1.3 \\
\hline 5519.20 & 18113.6 & w & 3 , & 0 & 0.6 \\
\hline 5506.17 & 18156.4 & $w$ & 6 & 2 & -0.7 \\
\hline 5492.90 & 18200.3 & $w$ & 5 , & 1 & 0.3 \\
\hline 5480.00 & 18243.1 & $w$ & 4, & 0 & 0.1 \\
\hline 5454.00 & 18330.1 & w & 6 & 1 & 1.5 \\
\hline 5441.61 & 18371.8 & ww & 5 , & 0 & -0.5 \\
\hline 5419.09 & 18448.2 & $w$ & 11 , & 4 & -1.9 \\
\hline
\end{tabular}


TABLE VII (Continued)

Band Heads of the B-X System

\begin{tabular}{|c|c|c|c|c|c|}
\hline$\lambda_{\text {air }}(\stackrel{0}{A})$ & $v_{v a c}\left(\mathrm{~cm}^{-1}\right)$ & Intensity & $v !$ & $v^{\prime \prime}$ & $v_{\text {obs }}{ }^{-v_{c a l e}}$ \\
\hline 5416.76 & 18456.1 & $w$ & 7. & 1 & -0.6 \\
\hline 5403.84 & 18500.2 & $w$ & 6 & 0 & -0.8 \\
\hline 5395.44 & 18529.0 & $w$ & 13 & 5 & -0.8 \\
\hline 5379.43 & 18584.2 & $w$ & 8, & 1 & 0.2 \\
\hline 5374.94 & 18599.7 & $w$ & - & - & - \\
\hline 5366.49 & 18629.0 & $w$ & 7, & 0 & 0.0 \\
\hline 5356.10 & 18665.1 & w & 10 & 2 & -0.2 \\
\hline 5346.35 & 18699.2 & $w$ & 13 & 4 & 0.3 \\
\hline 5343.90 & 18707.7 & $w$ & - & - & - \\
\hline 5333.38 & 18744.6 & $w$ & 12 & 3 & -0.1 \\
\hline 5330.13 & 18756.1 & $w$ & 8, & 0 & -0.2 \\
\hline 5320.18 & 18791.1 & w & 11 & 2 & 0.4 \\
\hline 5294.35 & 18882.8 & $w$ & 9, & 0 & -0.2 \\
\hline 5285.04 & 18916.1 & $w$ & 12 & 2 & 0.7 \\
\hline 5259.17 & 19009.1 & w & 10 & 0 & 0.0 \\
\hline 5242.99 & 19067.8 & w & 16 & 4 & 0.6 \\
\hline 5224.84 & 19134.0 & w & 11 & 0 & -0.5 \\
\hline 5190.84 & 19259.4 & $w$ & 12 & 0 & 0.2 \\
\hline 5170.21 & 19336.2 & $w$ & 14 & 1 & 1.8 \\
\hline
\end{tabular}


TABLE VII (Continued)

Band Heads of the B-X System

\begin{tabular}{|c|c|c|c|c|c|}
\hline$\lambda_{\text {air }}\left(\begin{array}{l}0 \\
)\end{array}\right.$ & $v_{v a c}\left(\mathrm{~cm}^{-1}\right)$ & Intensity & $v:$ & $v^{\prime \prime}$ & $v_{\text {obs }}{ }^{-v_{c a l c}}$ \\
\hline 5164.16 & 19358.9 & $w$ & - & - & - \\
\hline 5157.65 & 19383.3 & m & 13 & 0 & 0.0 \\
\hline 5137.70 & 19458.6 & $w$ & 15 & 1 & 1.4 \\
\hline 5131.77 & 19481.0 & w & 18, & 3 & 1.5 \\
\hline 5124.60 & 19508.3 & $w^{\star \star}$ & 14, & 0 & 1.6 \\
\hline 5119.05 & 19529.5 & $w$ & 17 , & 2 & 0.2 \\
\hline 5105.90 & 19579.8 & $w$ & 16 , & 1 & 0.5 \\
\hline 5092.74 & 19630.3 & $w$ & 15, & 0 & 0.8 \\
\hline 5074.30 & 19701.7 & $w$ & 17 & 1 & 0.9 \\
\hline 5061.29 & 19752.3 & w & 16 , & 0 & 0.7 \\
\hline 5056.46 & 19771.2 & w & 19, & 2 & 0.7 \\
\hline 5043.20 & 19823.2 & w & 18 & 1 & 1.5 \\
\hline 5030.33 & 19873.9 & $m$ & 17, & 0 & 0.8 \\
\hline 5025.84 & 19891.6 & $w$ & 20 & 2 & 1.5 \\
\hline 5012.94 & 19942.8 & $w$ & 19 , & 1 & 0.8 \\
\hline 4999.70 & 19995.7 & $w$ & 18 , & 0 & 1.7 \\
\hline 4995.98 & 20010.5 & $w$ & 21 , & 2 & 1.3 \\
\hline 4982.87 & 20063.2 & $w$ & 20 , & 1 & 1.6 \\
\hline 4970.33 & 20113.8 & $w^{\star \star}$ & 19 , & 0 & -0.5 \\
\hline
\end{tabular}


TABLE VII (Continued)

Band Heads of the B-X System

\begin{tabular}{|c|c|c|c|c|c|}
\hline$\lambda_{\text {air }}(\AA)$ & $v_{v a c}\left(\mathrm{~cm}^{-1}\right)$ & Intensity & $v !$ & $v^{\prime \prime}$ & $\nu_{\mathrm{obs}^{-}}^{-v_{c a l c}}$ \\
\hline 4966.85 & 20127.9 & $w$ & 22 & 2 & 0.3 \\
\hline 4953.68 & 20181.4 & $w$ & 21, & 1 & 0.7 \\
\hline 4950.15 & 20195.8 & ww & 24, & 3 & 3.6 \\
\hline 4937.92 & 20245.8 & nw & 23, & 2 & 0.2 \\
\hline 4924.82 & 20299.7 & $w$ & 22. & 1 & 0.6 \\
\hline 4899.71 & 20403.7 & $w$ & - & - & - \\
\hline 4898.12 & 20410.3 & $w$ & - & - & - \\
\hline 4896.52 & 20417.0 & $w$ & 23, & 1 & -0.1 \\
\hline 4894.62 & 20424.9 & $w$ & 26 , & 3 & -0.6 \\
\hline 4868.42 & 20534.8 & $w$ & 24 , & 1 & 0.4 \\
\hline 4840.88 & 20681.7 & w & 25 , & 1 & 0.4 \\
\hline 4839.65 & 20656.9 & w & 28 , & 3 & -0.1 \\
\hline
\end{tabular}

* The notation for the intersities is the same as the one given in table I . 
Vibrational Scheme of the B - X System

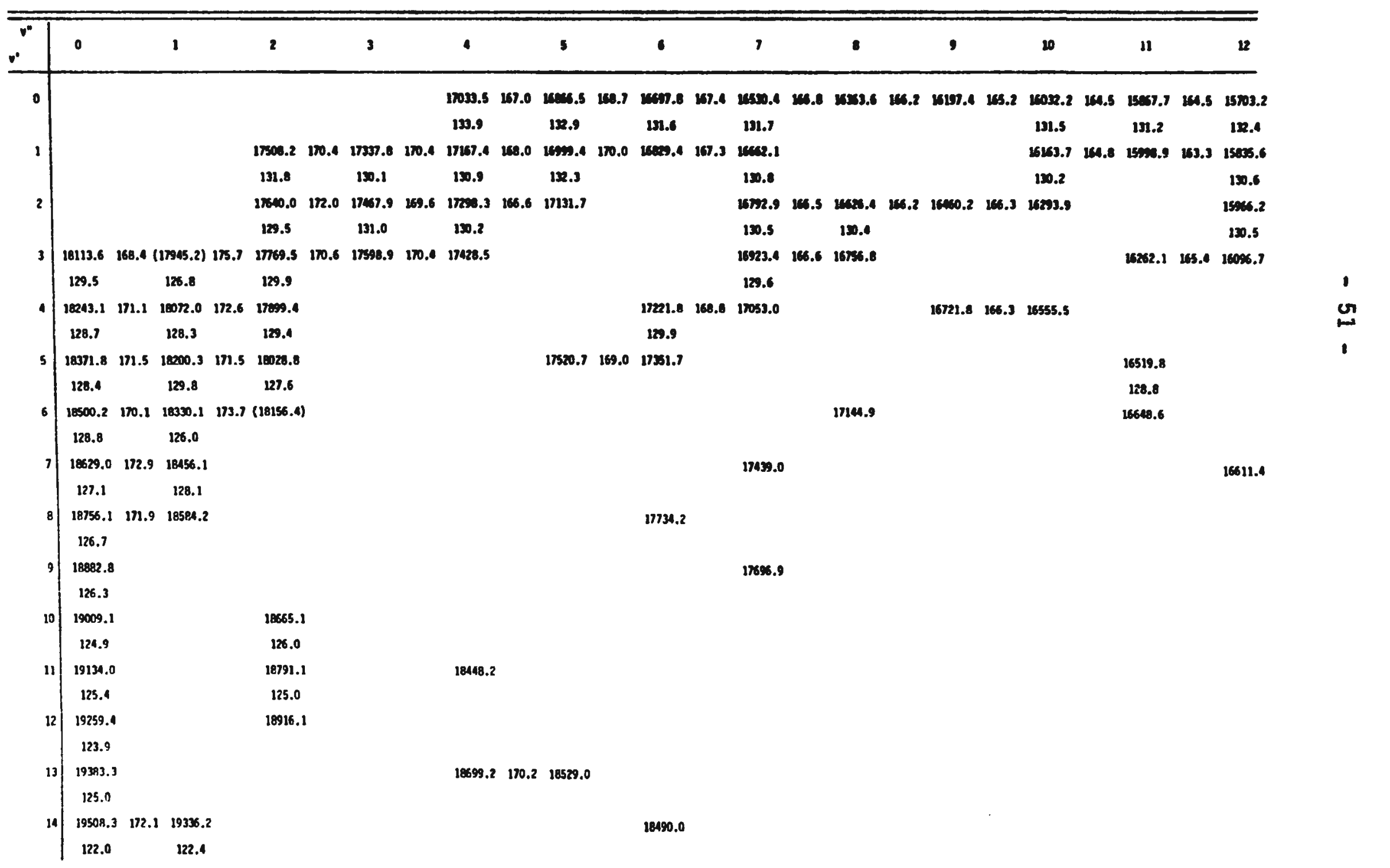


Vibrational Jcheme of the B - X System

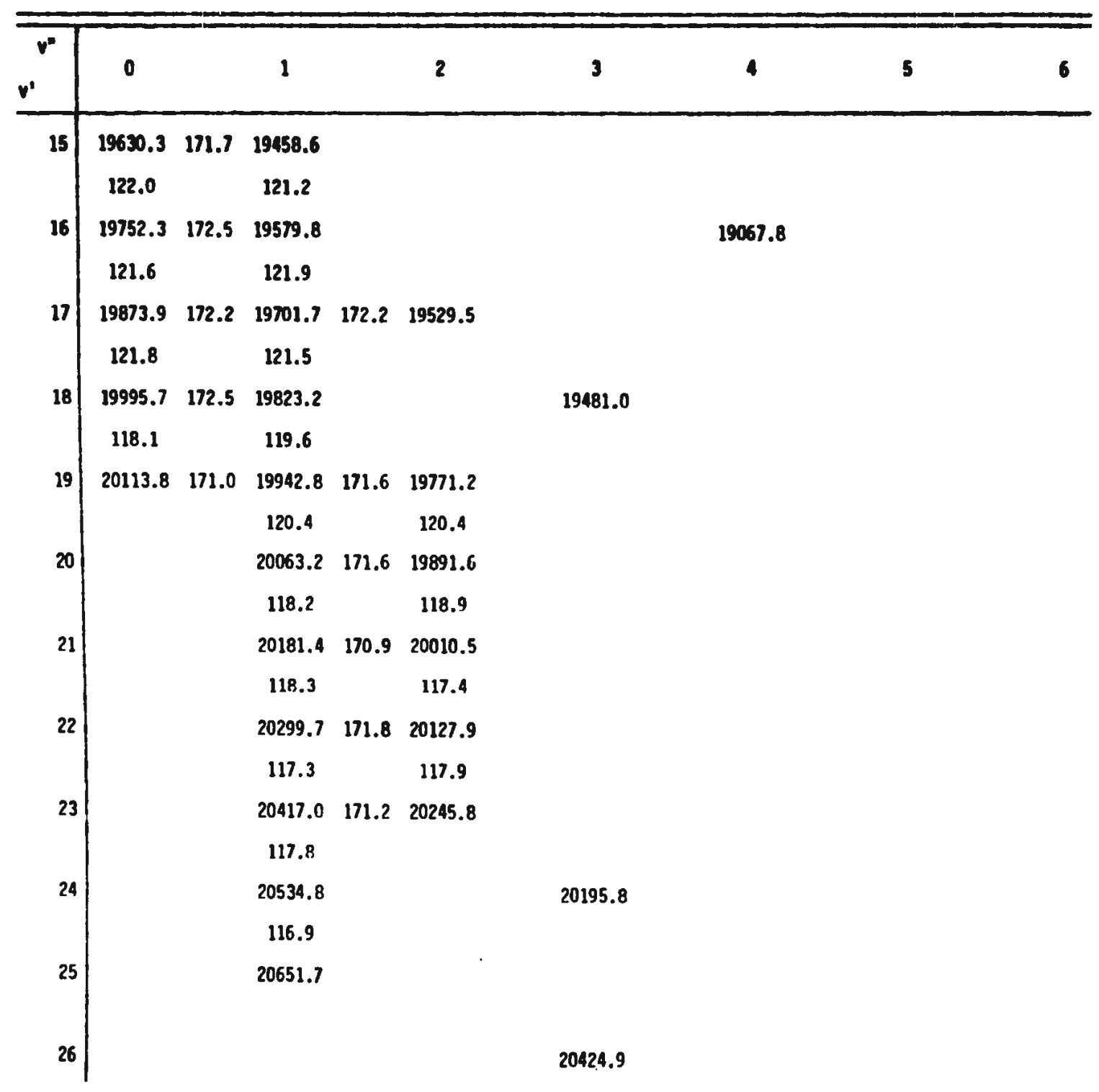


TABLE VIII (Continued)

Vibrational Scheme of the B - X System

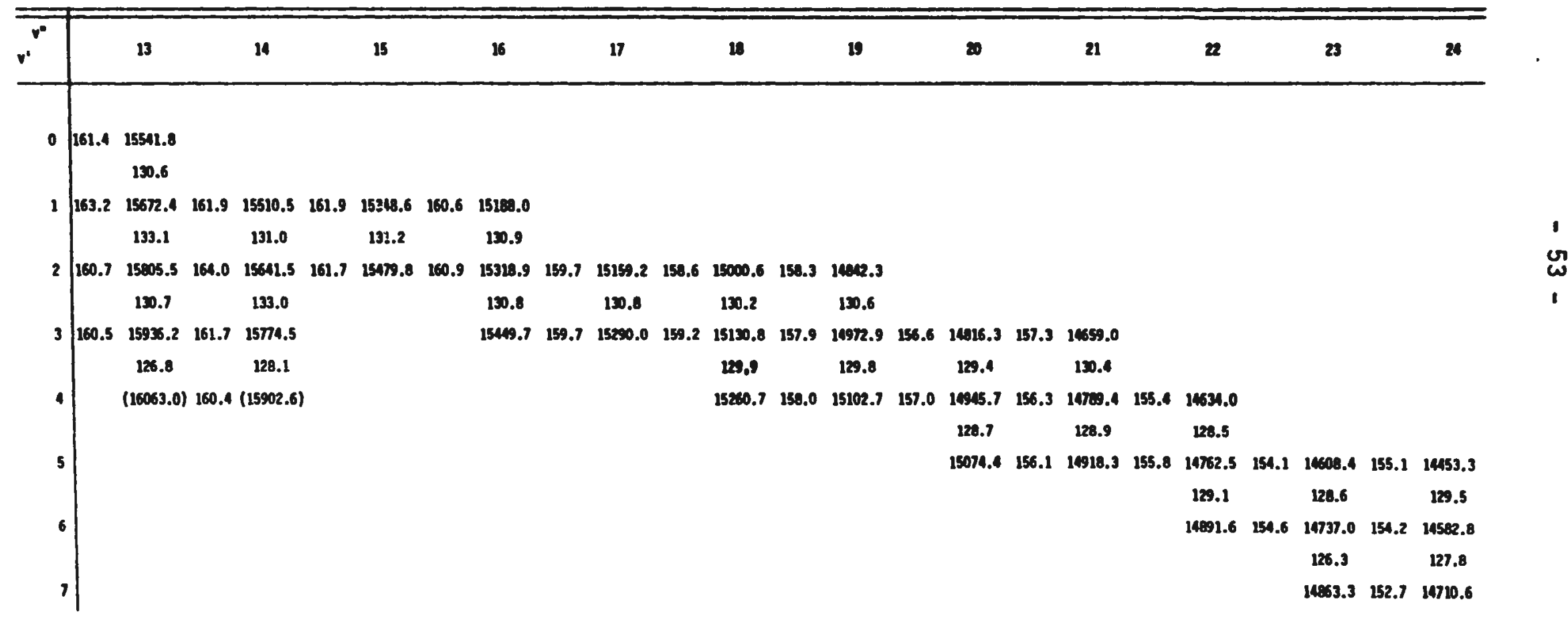


TABLE VIII (Continued)

Vibrational Scheme of the $B$ - X System

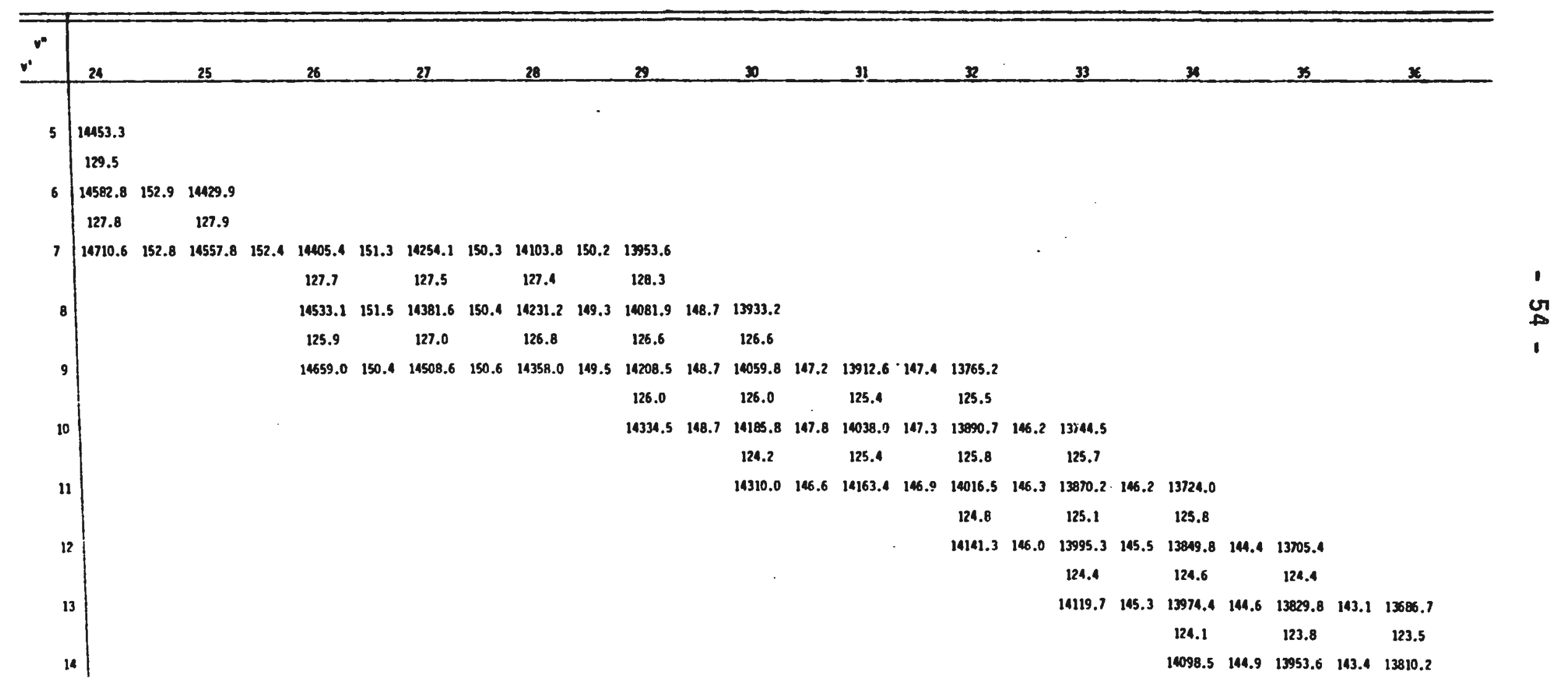


TABLE VIII (Continued)

Vibrational Scheme of the B - X System

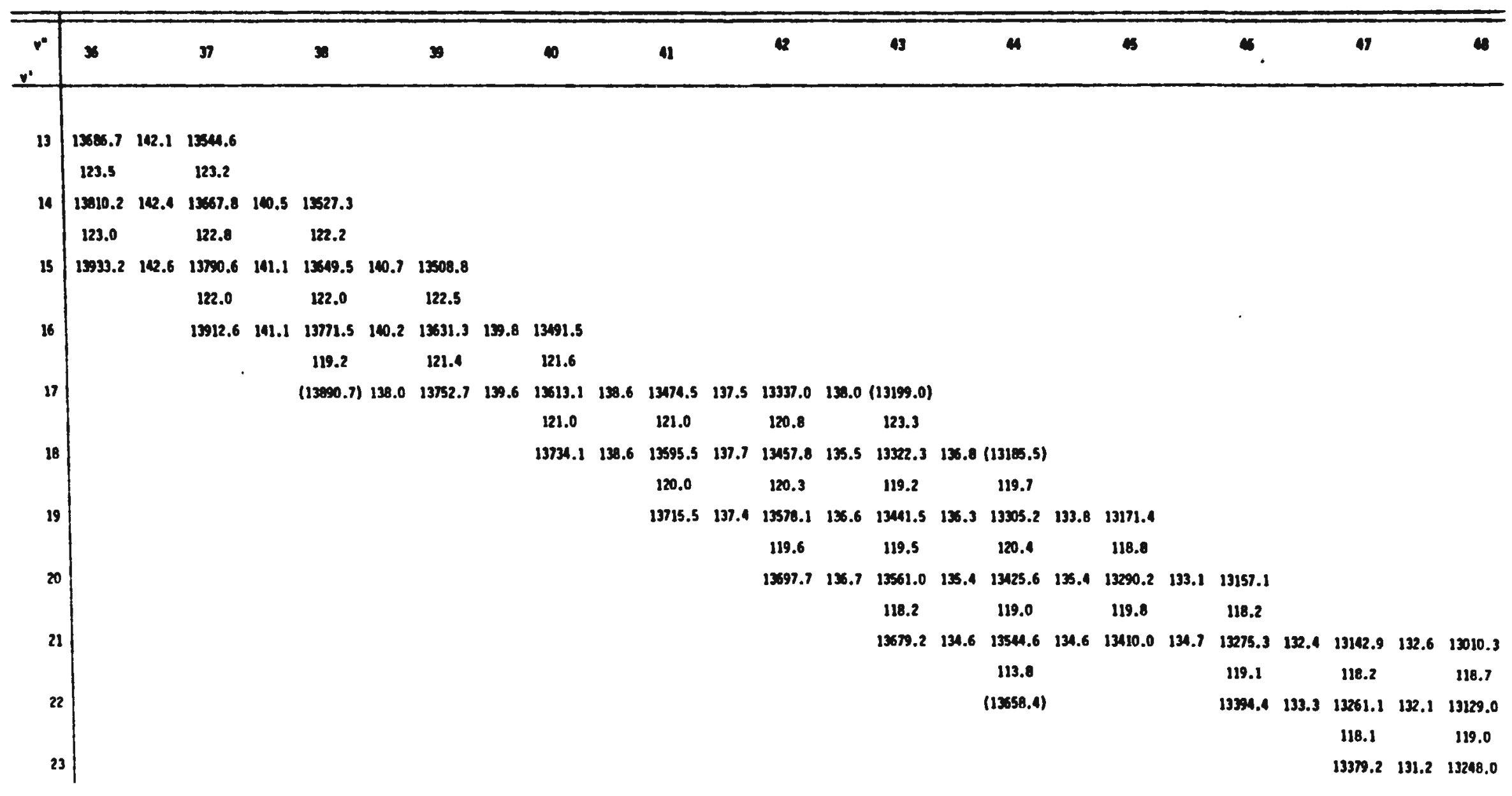


Vibrational Scheme of the B - X System

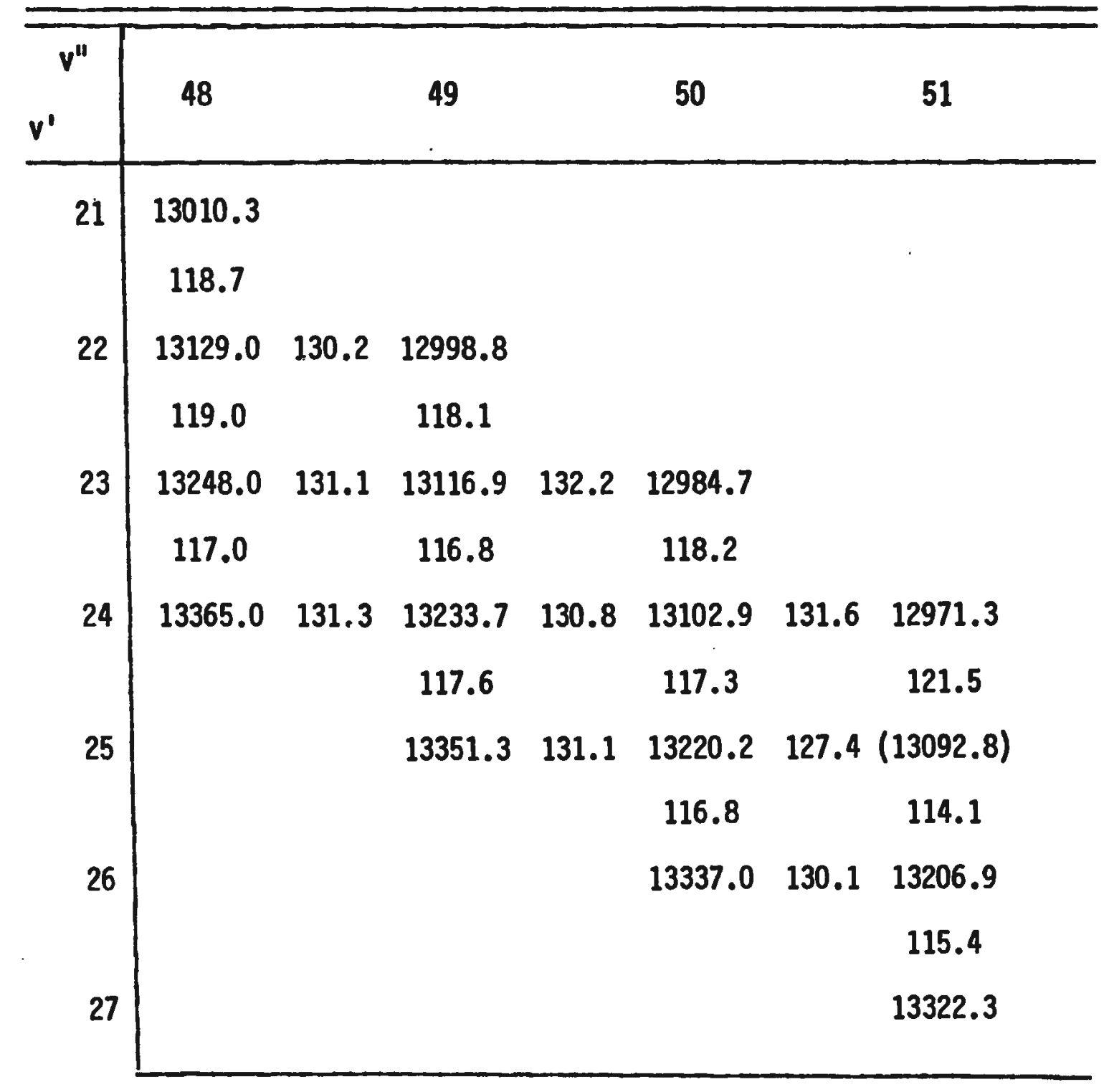

The figures in parentheses are less accurate than the others. 


\section{CHAPTER IV}

\section{DISCUSSION ON THE ELECTRONIC STATES OF $\mathrm{Bi}_{2}$}

\subsection{Summary of the Electronic States of $\mathrm{Bi}_{2}$ :}

As described in Chapter III, the present work contributed considerably to the spectroscopic knowledge of the $\mathrm{Bi}_{2}$ molecule. Three band systems, observed for the first time, have been analyzed and vibrational constants derived. Accurate vibrational constants for one of the known systems of $\mathrm{Bi}_{2}$ have also been derived from the preseni emission data. It is therefore considered worthwhile to summarize the existing data on the $\mathrm{Bi}_{2}$ molecule. This information is presented in the following table and in Fig. 8.

\begin{tabular}{|c|c|c|c|c|c|c|}
\hline State & $\underline{\mathrm{T}}$ & $\omega_{e}$ & $\frac{\omega_{e} e_{e}}{m^{-1}}$ & $\omega_{e} y_{e}$ & $\begin{array}{l}\text { Observed } \\
\text { transition }\end{array}$ & References \\
\hline \multicolumn{7}{|c|}{ In addition a series of diffuse bands near $40200 \mathrm{~cm}^{-1}$. } \\
\hline (F) & -46000 & only par & tially a & malyzed & $(F)+X$ & Almy and Sparks (1933) \\
\hline$E$ & 42252 & 129 & 9.7 & & $E \leftarrow B$ & Almy and Sparks (1933) \\
\hline D & 36457 & 157 & 4.6 & & $D \leftarrow X$ & Almy and Sparks (1933) \\
\hline I & 33216.9 & 156.4 & 6.1 & & $I \rightarrow B$ & This thesis \\
\hline H & $(32591)$ & only one & $v^{\prime \prime}$ prog & iression & $H \rightarrow B$ & This thesis \\
\hline c & -32000 & $\begin{array}{l}\text { continuc } \\
\text { repulsi }\end{array}$ & $\begin{array}{l}\text { us absor } \\
\text { e state }\end{array}$ & ption, & $c \leftarrow x$ & Almy and Sparks (1933) \\
\hline G & 29609.0 & 107.0 & 0.2 & & $G \rightarrow B$ & This thesis \\
\hline B & 17739.5 & 132.571 & 0.3271 & 0.000524 & $B \leftrightarrow X$ & This thesis \\
\hline$x^{1} \Sigma_{g}^{+}$ & 0 & 173.132 & 0.4156 & 0.002437 & & This thesis \\
\hline
\end{tabular}


$T e^{\left(\mathrm{cm}^{-1}\right)}$

\section{0,000 -}

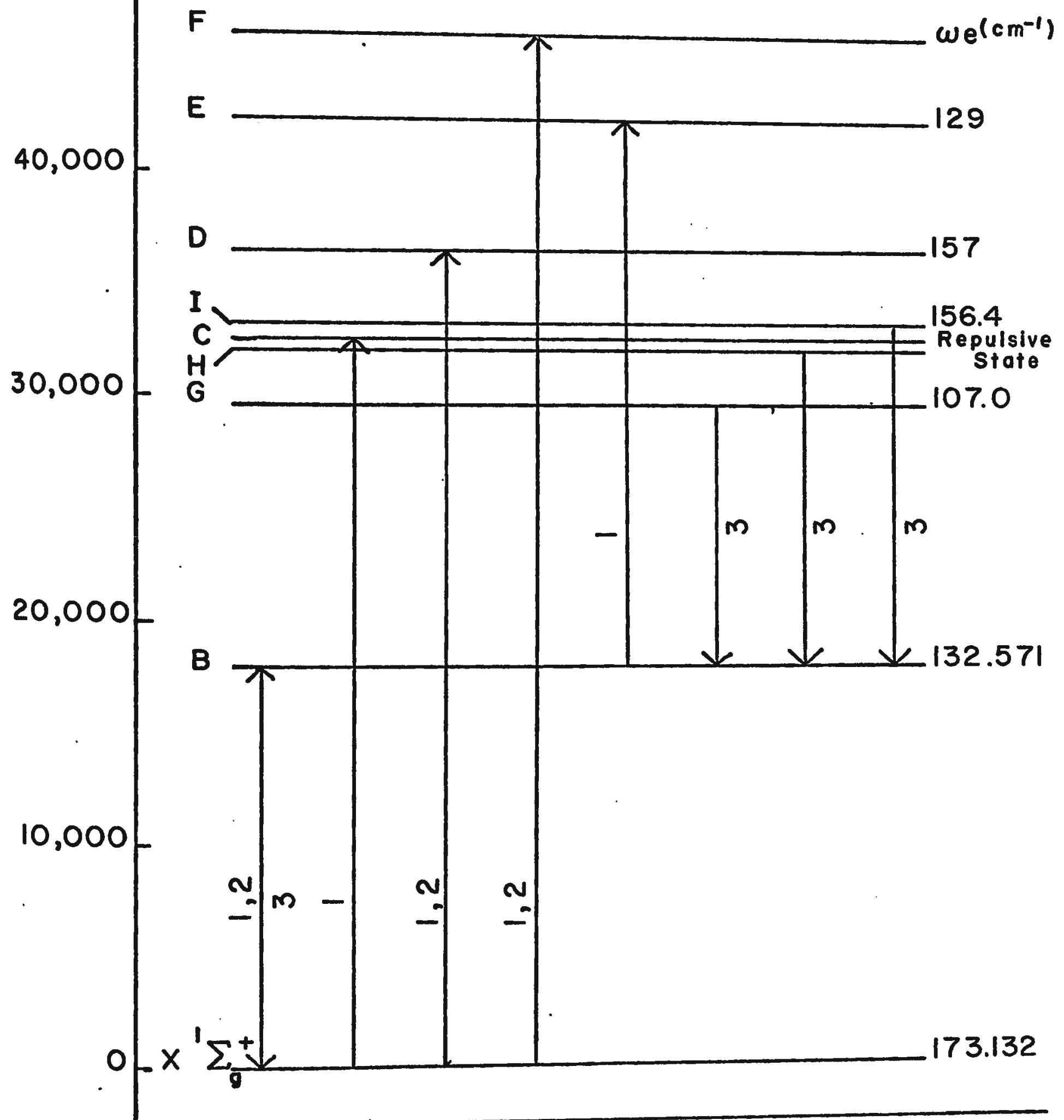

Fig. 8 Energy level diagram of the $\mathrm{Bi}_{2}$ molecule. 'Almy and Sparks (1933); ${ }^{2} \mathrm{Nakamura}$ and Shidei $(1934) ;{ }^{3}$ This thesis. 
4.2 Electronic Configurations and Molecular Terms of $\mathrm{Bi}_{2}$ :

To determine the nature of the electronic states of the observed transitions, it is necessary to do the rotational fine structure analyses of bands belonging to these transitions. Moderate dispersion used in the present work is not qui te adequate to make such an analysis possible for the $\mathrm{Bi}_{2}$ molecule. However, one can predict the possible electronic states of a molecule from the molecular orbital theory as well as from the separated atoms. We shall now consider, first, the number of low-lying states of $\mathrm{Bi}_{2}$ which may be predicted by the molecular orbital theory and, second, the number of states of $\mathrm{Bi}_{2}$ which can be formed from two bismuth atoms in their low-lying electronic states.

(i) From the molecular orbital theory:

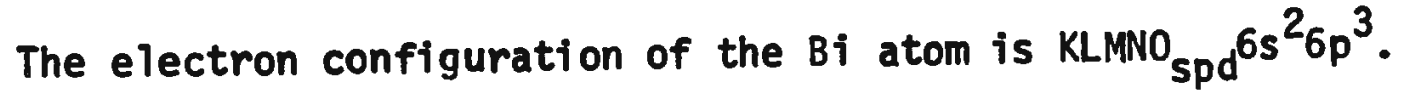
In deriving the possible molecular electronic states of the $\mathrm{Bi}_{2}$ molecule, we need not take into account the electrons of the inner $K, L, M, N, O$ shells of the individual $B i$ atoms since these atomic shells are unaffected in the molecular formation. The 'united atom' method of writing the electron configuration for molecules is therefore not a good approximation in this case. Using the standard notation (Herzberg, 1950, Chapter VI), the electron configuration and the term type of the lowest electronic state of $\mathrm{Bi}_{2}$ may be written as

$$
\text { KKLLMMNN } 0_{s p d} 0_{s p d}\left(\sigma_{g} 6 s\right)^{2}\left(\sigma_{u} 6 s\right)^{2}\left(\pi_{u} 6 p\right)^{4}\left(\sigma_{g} 6 p\right)^{2}:{ }^{1} \Sigma_{g}^{+} \text {. }
$$


Therefore, the ground electronic state $\mathrm{X}_{\text {of }} \mathrm{Bi}_{2}$ is a $\mathbf{l}_{\Sigma_{g}^{+}}^{+}$state. The first excited electron configurations of $\mathrm{Bi}_{2}$ are

$$
\text { KK …... }\left(\sigma_{g} 6 s\right)^{2}\left(\sigma_{u} 6 s\right)^{2}\left(\pi_{u} 6 p\right)^{4}\left(\sigma_{g} 6 p\right)\left(\pi_{g} 6 p\right): 3_{\pi_{g}}, 1^{1} \pi_{g} \text {, }
$$

and

$$
\begin{aligned}
& \text { KK ….. }\left(\sigma_{g} 6 s\right)^{2}\left(\sigma_{u} 6 s\right)^{2}\left(\pi_{u} 6 p\right)^{3}\left(\sigma_{g} 6 p\right)^{2}\left(\pi_{g} 6 p\right): 1_{\Sigma_{u}}^{+}, 3_{\Sigma_{u}}^{+}, 1_{\Sigma_{u^{\prime}}}, 3_{\Sigma_{u}^{-}} \\
& { }^{1} \Delta_{u},{ }^{3} \Delta_{u}
\end{aligned}
$$

Higher excited states are obtained by bringing the emission electron taken from the $\sigma_{g} 6 p$ or the $\pi_{u} 6 p$ or the $\sigma_{u} 6 s$ shells to higher and higher orbitals. The number of states resulting even from a few of these configurations is very large and does not allow a unique correlation with the numerous observed states. However, if the molecule under consideration is very simple, for example, $\mathrm{H}_{2}$ or $\mathrm{He}_{2}$, a unique correlation is possible. In the case of $\mathrm{Bi}_{2}$, the observed low excited states B, G, C, H, I, D (Fig. 8) may probably be identified with those derived from the configurations (2) and (3).

(ii) From the States of Separated Bi Atoms:

If $L_{1}$ and $L_{2}$ are the quantum numbers of the orbital angular momenta of the two atoms and $M_{L_{1}}$ and $M_{L_{2}}$ their components in the direction of the internuclear axis, then the resultant orbital angular momentum $M_{L_{1}}+M_{L_{2}}$ anid the quantum number $\Lambda$ of the molecule is

$$
\Lambda=\left|M_{L_{1}}+M_{L_{2}}\right|
$$


The possible $\Lambda$ values are obtained from all possible combinations of the individual $M_{L}$ values. States with different $\Lambda$ values correspond to different molecular electronic states. States which differ only in the sign of both $M_{L_{1}}$ and $M_{L_{2}}$ have equal energies if $M_{L_{1}}+M_{L_{2}} \neq 0$ and are said to be degenerate with each other. For $\Lambda=0$, each combination corresponds to a different molecular state $\left(\Sigma^{+}\right.$or $\left.\Sigma^{-}\right)$. The resulting spin quantum number of the molecule is obtained from the two spin vectors $S_{1}$ and $S_{2}$ of the separated atoms as

$$
s=\left(s_{1}+s_{2}\right),\left(s_{1}+s_{2}-1\right), \ldots \ldots,\left|s_{1}-s_{2}\right|
$$

Each molecular state having a specific $\Lambda$ value occurs with each of the multiplicities $2 S+1$ where $S$ is given by (5).

Making use of the above considerations as well as the socalled Wigner-Witmer correlation rules (see Herzberg, 1950, Chapter VI) the number of states of the $\mathrm{Bi}_{2}$ molecule which can be formed from two Bi atoms in their low-lying ${ }^{4} S_{u},{ }^{2} D_{u}$, and ${ }^{2} P_{u}$ states may be written in the following way:

$$
\begin{aligned}
& { }^{4} S_{u}+{ }^{4} S_{u}+{ }^{1} \Sigma_{g}^{+}, 3_{\Sigma_{u}}^{+},{ }^{5} \Sigma_{g}^{+},{ }^{7} \Sigma_{u}^{+} ; \\
& { }^{4} S_{u}+{ }^{2} D_{u}+{ }^{3} \Sigma_{g},{ }^{3}{ }_{1},{ }^{3} \Delta_{g},{ }^{5} \Sigma_{g},{ }^{5} \pi_{g},{ }^{5} \Delta_{g}, \\
& 3_{\Sigma_{u}}, 3_{I_{u}}, 3_{\Delta_{u}}, 5_{\Sigma_{u}}, 5_{I_{u}},{ }^{5}{ }_{u} \text {; }
\end{aligned}
$$


(8)

$$
\begin{aligned}
& { }^{4} s_{u}+{ }^{2} P_{u}+{ }^{3} \Sigma_{g}^{-},{ }^{3} \pi_{g},{ }^{5} \Sigma_{g}^{-},{ }^{5} \pi_{g}, \\
& 3_{\Sigma_{u}^{-}}, 3^{3} \pi_{u}, 5_{\Sigma_{u}}^{-},{ }^{5} \pi_{u} ;
\end{aligned}
$$

(9)

$$
\begin{aligned}
& { }^{2} D_{u}+{ }^{2} D_{u}+{ }^{1} \Sigma_{g}^{+}(3), 1_{\Sigma_{u}^{-}}^{-}(2), 1_{I_{g}}(2), 1_{\Pi_{u}}(2),{ }^{1} \Delta_{g}(2), \\
& { }^{1}{ }_{u}, 1_{\Phi_{g}}, 1_{\Phi_{u}},{ }^{1}{ }_{g} \text {, } \\
& { }^{3} \Sigma_{u}^{+}(3),{ }^{3} \Sigma_{g}^{-}(2),{ }^{3} \pi_{u}(2),{ }^{3} \pi_{g}(2),{ }^{3} \Delta_{u}(2) \text {, } \\
& { }^{3}{ }_{g},{ }^{3} \Phi_{u}, 3_{\Phi_{g}},{ }^{3} r_{u} \text {. }
\end{aligned}
$$

Similarly, the states arising from the combinations ${ }^{2} D_{u}+{ }^{2} P_{u}$ and ${ }^{2} \mathrm{P}_{u}+{ }^{2} \mathrm{P}_{\mathrm{u}}$ may also be obtained. The ground electronic state $\mathrm{X}$ of $\mathrm{Bi}_{2}$ may be identified as the ${ }^{1} \Sigma_{g}^{+}$state arising from two normal $B i\left({ }^{4} S\right)$ atoms. The excited states $B, G, C, H, I$, etc., may correspond to those states which can be derived from the atomic states ${ }^{4} S,{ }^{2} \mathrm{D}$, and $2 p$ as shown above. 


\section{APPENDIX \\ VIBRATIONAL STRUCTURE OF ELECTRONIC SPECTRA}

The total energy $E$ of a molecule can be expressed, to a good approximation, as the sum of three component parts, $E=E_{e}+E_{v}+E_{r}$, where $E_{e}$ is the electronic energy, $E_{v}$ is the vibrational energy and $E_{r}$ is the rotational energy. The translational energy $E_{t}$, and the energy of the nuclei $E_{n}$, of the molecule are assumed to be zero and hence neglected in the above sum. When our interest is in the vibrational structure of electronic spectra, the rotational energy term $E_{r}$ can also be omitted. Then the frequency $\nu\left(\mathrm{cm}^{-1}\right)$ of a band head in an electronic band system is represented as

$$
v=\left(T_{e}^{\prime}-T_{e}^{\prime \prime}\right)+\left(G^{\prime}(v)-G^{\prime \prime}(v)\right)
$$

where $T_{e}=\frac{E_{e}}{c h}, G(v)=\frac{E_{v}}{c h}, h$ is Planck!s constant and $c$ is the velocity of light. Here the single-primed letters refer to the upper electronic state and the double-primed letters refer to the lower electronic state. Putting $T_{e}^{\prime}-T_{e}^{\prime \prime}=v_{e}$, eq. (1) can be written as

$$
\begin{aligned}
v & =v_{e}+G^{\prime}(v)-G^{\prime \prime}(v) \\
\text { or } v_{e} & =v-\left[G^{\prime}(v)-G^{\prime \prime}(v)\right] .
\end{aligned}
$$

For an anharmonic oscillator, the vibrational term value $G(v)$ for an electronic state is given by 
$-64-$

(4)

$$
\begin{aligned}
G(v)= & \omega_{e}\left(v+\frac{1}{2}\right)-\omega_{e} x_{e}\left(v+\frac{1}{2}\right)^{2}+\omega_{e} y_{e}\left(v+\frac{1}{2}\right)^{3}+\omega_{e} z_{e}\left(v+\frac{1}{2}\right)^{4} \\
& +a\left(v+\frac{1}{2}\right)^{5}+\ldots
\end{aligned}
$$

Substituting eq. (4) in eq.. (2) and retaining terms of $v+\frac{3}{2}$ up to the 5 th power, we get

(5)

$$
\begin{aligned}
v= & v_{e}+\omega_{e}^{\prime}\left(v^{\prime}+\frac{1}{2}\right)-\omega_{e}^{\prime} x_{e}^{\prime}\left(v^{\prime}+\frac{1}{2}\right)^{2}+\omega_{e}^{\prime} y_{e}^{\prime}\left(v^{\prime}+\frac{1}{2}\right)^{3}+w_{e}^{\prime} z_{e}^{\prime}\left(v^{\prime}+\frac{1}{2}\right)^{4} \\
& +a^{\prime}\left(v^{\prime}+\frac{1}{2}\right)^{5}-\left[\omega_{e}^{\prime \prime}\left(v^{\prime \prime}+\frac{1}{2}\right)-\omega_{e}^{\prime \prime} x_{e}^{\prime \prime}\left(v^{\prime \prime}+\frac{1}{2}\right)^{2}+\omega_{e}^{\prime \prime} y_{e}^{\prime \prime}\left(v^{\prime \prime}+\frac{1}{2}\right)^{3}\right. \\
& \left.+\omega_{e}^{\prime \prime} z_{e}^{\prime \prime}\left(v^{\prime \prime}+\frac{1}{2}\right)^{4}+a^{\prime \prime}\left(v^{\prime \prime}+\frac{1}{2}\right)^{5}\right] .
\end{aligned}
$$

The vibrational quanta $\Delta G_{v}+\frac{1}{2}$ for a given electronic state aredefined by the relation

(6)

$$
\begin{aligned}
\Delta G_{v+\frac{1}{2}} & =G(v+1)-G(v), \\
& =b-c\left(v+\frac{1}{2}\right)+d\left(v+\frac{1}{2}\right)^{2}+e\left(v+\frac{1}{2}\right)^{3}+f\left(v+\frac{1}{2}\right)^{4},
\end{aligned}
$$

where $b=\omega_{e}-\omega_{e} x_{e}+\omega_{e} y_{e}+\omega_{e} z_{e}+a$

$$
c=2 \omega_{e} x_{e}-3 \omega_{e} y_{e}-4 \omega_{e} z_{e}-5 a
$$

(7)

$$
\begin{aligned}
& d=3 \omega_{e} y_{e}+6 \omega_{e} z_{e}+10 a \\
& e=4 \omega_{e} z_{e}+10 a \\
& f=5 a
\end{aligned}
$$


$-65-$

From relations (7) we get the following expressions for the vibrational anharmonicities and the vibrational frequency:

$$
\begin{aligned}
& a=f / 5 \\
& \omega_{e} z_{e}=e / 4-f / 2 \\
& \omega_{e} y_{e}=\frac{1}{3}(d+f)-e / 2 \\
& \omega_{e} x_{e}=\frac{1}{2}(c+d)-e / 4 \\
& \omega_{e}=b+c / 2+d / 6-f / 30 .
\end{aligned}
$$

If we put $\omega_{e} y_{e}=\omega_{e} z_{e}=a=0$ in eq. (4), eq... (6) reduces to

(9) $\Delta G_{v}+\omega_{2}=\omega_{e}-\omega_{e} e_{e}-2 \omega_{e} x_{e}\left(v+\frac{3}{2}\right) \cdot$ 


\section{ACKNOWLEDGMENTS}

The author is greatly indebted to his Supervisor, Dr. S. P. Reddy for his constant interest and active guidance in the present research and for his assistance in the preparation of the thesis.

The author is grateful to Dr. S. W. Breckon and Dr. C. W. Cho for their interest in this work. Thanks are also due to Professor P. D. P. Smith for helpful discussions on the use of the Microwave Power Generator.

The financial assistance received from the Canadian International Development Agency under the Colombo Plan is gratefully acknowledged. The assistance received from the technical personnel of the Physics Department is gratefully acknowledged. Thanks are also due to Mr. D: Seymour for his skillful glassblowing.

Thanks are extended to Mr. M. Azam for typing the tables of this thesis. Finally, the author is indebted to his wife who made some calculations for this thesis. 


\section{FEFEPLI:CES}

A7my, G. M. 1937. J. Phys. Chem. 41, 47.

r.7my, G. "., and Sparts, F.". 1933. Pnys. Rev. 44, 365.

Herzberq, f., Snectra of Iiatomic l'olecules (D. Van ilostrand Company,

Inc., "ew Jersey, iew York, 1950).

Jevons, H., Fand Snectra of niatomic Molecules (Phys. Soc., London, 1932).

Kavser, I'., Tahelle der Schwinqungszahlen (Verlag Von S. Hirzel in Leinziq, revised edition, 1944).

lakamura, G., and Shidei, T. 1034. Japanese J. Phys. 10, 11. 


\section{GENERAL REFERENCES}

Gatterer, A., and Junkes, J. Arc Spectrum of Iron (Specola Vaticana, Citta Del Vaticano, 1956).

Gaydon, A. G., Dissociation Energies and Spectra of Diatomic Molecules (Chapman and Hall Ltd., 1947).

Harrison, G. R., Lord, R. C., and Loofbourow, J. R. Practical Spectroscopy (Prentice-Hall, Inc., New York, 1948).

Moore, C. E., Atomic Energy Levels (Circular 467 bf the Natioñale Bureau of Standards, 1969).

Mulliken, R. S., "Interpretation of Band Spectra", Part I, II(a) and II(b), Rev. Mod. Phys. Vol. 2, (1930)

Part II (c)

Part III

$$
\begin{aligned}
& \text {, " " Vol. 3, (1931) } \\
& \text {, " " Vol. 4, (1932) }
\end{aligned}
$$

Mulliken, R. S., "Solved and un-solved problems in the spectra of diatomic molecules", J. Phys. Chem. 41, (1937).

Pearse, R. W. B., "Fundamental Research in Molecular Spectra", J. Opt. Soc. America, 41, 148, (1951).

Pearse, R. W. B., and Gaydon, A. G. The Identification of Molecular Spectra, 2nd Ed. (Chapman and Hall Ltd., 1963).

Sawyer, R. A., Experimental Spectroscopy, 2nd Ed. (Chapman and Hall Ltd., 1951). 

